\title{
A Review of Groundwater Management Models with a Focus on IoT-Based Systems
}

\author{
Banjo Ayoade Aderemi ${ }^{1, *}$, Thomas Otieno Olwal ${ }^{1}$, Julius Musyoka Ndambuki ${ }^{2}$ and Sophia Sudi Rwanga ${ }^{3}$ \\ 1 Department of Electrical Engineering, Tshwane University of Technology, Pretoria 0183, South Africa; \\ OlwalTO@tut.ac.za \\ 2 Department of Civil Engineering, Tshwane University of Technology, Pretoria 0183, South Africa; \\ NdambukiJM@tut.ac.za \\ 3 Department of Civil Engineering, Vaal University of Technology, Vanderbijlpark 1900, South Africa; \\ sophiar@vut.ac.za \\ * Correspondence: ayoadebanjo93@hotmail.com; Tel.: +27-78-354-2284
}

Abstract: Globally, groundwater is the largest distributed storage of freshwater and plays an important role in an ecosystem's sustainability in addition to aiding human adaptation to both climatic change and variability. However, groundwater resources are dynamic and often change as a result of land usage, abstraction, as well as variation in climate. To solve these challenges, many conventional solutions, such as certain numerical techniques, have been proffered for groundwater modelling. The global evolution of the Internet of Things (IoT) has enhanced the culture of data gathering for the management of groundwater resources. In addition, efficient data-driven groundwater resource management relies hugely on information relating to changes in groundwater resources as well as their availability. At the moment, some studies in the literature reveal that groundwater managers lack an efficient and real-time groundwater management system which is needed to gather the required data. Additionally, the literature reveals that the existing methods of collecting data lack the required efficiency to meet computational model requirements and meet management objectives. Unlike previous surveys, which solely focussed on particular groundwater issues related to simulation and optimisation management methods, this paper seeks to highlight the current groundwater management models as well as the IoT contributions.

Keywords: Internet of Things (IoT); groundwater level; groundwater resource; groundwater management models; groundwater monitoring system; wireless sensor network

\section{Introduction}

About approximately one-third of global freshwater consumption depends on groundwater resources; thus, it has become an important source of freshwater globally [1]. In the water cycle, the freshwater resource accounts for approximately $4 \%$ of the total water available on earth, while the remaining $96 \%$ is salty, found within seas and oceans [2]. Meanwhile, only about $0.001 \%$ of water is available as a groundwater resource that is hidden underground, while $75 \%$ is ice and about $25 \%$ is liquid water [3]. Therefore, groundwater resources constitute approximately $98 \%$ of all fresh liquid water available on earth [4]. Since both plants and animals depend on water, the interaction between surface water systems and groundwater resources is essential for basic life on the earth. This makes groundwater the largest distributable storage of freshwater which plays an important role in an ecosystem's sustainability as well as in aiding human adaptation to both climatic change and variability [5]. Human beings largely depend on groundwater resources as a major supply of their drinking water. Thus, the efficient measurement, monitoring, and management of groundwater resources are crucial to ensure future sustainability. Nonetheless, human activities and a lack of planning for these activities have led to groundwater quantity shortage in the aquifer, land subsidence, saltwater intrusion, high cost of water production, overexploitation, and unhygienic and quality contamination of 
water [6-16]. Additionally, the management and sustainability of groundwater resources is a global critical issue. This is in line with goal six of the Sustainable Development Goals (SDGs) adopted by the United Nations General Assembly which seeks to achieve a universal reduction in water scarcity, sustainable water management, and to substantially increase the efficiency of water usage by 2030 [17].

In the aquifer, the system of groundwater is slow and dynamic. This is because it responds to variation in hydrological stresses like climate change, land use, and abstraction among other things in two ways $[18,19]$. The first way is to balance out the re-charge and discharge of the aquifer system in a process known as an equilibrium state, thus, allowing the aquifer to exist indefinitely, or secondly, when the hydrological stress is so large and beyond the equilibrium state it leads to a finite aquifer's life span [20,21]. Depending on the region, the replenishment of a utilised groundwater resource is typically slow, thus leading to a reduction in the level of resources. In addition to usage, as a result of the high non-linear and non-stationary nature of groundwater resources in time series, its efficient management depends on various complex factors such as precipitation and other environmental factors [22]. Consequently, groundwater models are essential management tools that are used to locate these adverse effects and the ideal balance of groundwater abstraction on the aquifer [23]. Furthermore, groundwater modelling assists in determining an aquifer's response to hydrological conditions as well as promoting the sustainable management of groundwater resources [24]. Therefore, groundwater models are crucial to ensuring a sustainable future for water scarcity reduction and overexploitation as well as for the improvement in the efficient use of water resources. Consequently, it is of vital importance that an effective management model for accurate groundwater-level management models be developed $[25,26]$.

The measurement of groundwater levels is important to avoid depletion of groundwater resources as earlier stated [2]. Groundwater level measurement assists in determining the hydrological stress acting in an aquifer and provides data for efficient management. For long-term forecast and management, groundwater level measurements supply data to develop a groundwater model $[27,28]$. This has made groundwater management models become a standard instrument used by water managers and professionals to solve most groundwater-related problems. Thus, there are many models, such as data-driven models, numerical models, as well as nonlinear models, which are used for groundwater modelling [29-31]. However, it is important to understand the nature and characteristics of groundwater levels to be able to efficiently measure or model groundwater resources. Additionally, the nature of groundwater level measurement in time series is described to be non-stationary and non-linear which means it depends on various complex surrounding agents such as precipitation, intervening aquitards, groundwater aquifers, and other hydrogeological characteristics of the aquifers involved [32]. Additionally, the groundwater aquifers systems' interaction with the surface water at different temporal-spatial scales is described as intrinsic in heterogeneous systems that are strained by a knotty hydrogeological state $[33,34]$. Thus, the processes and the physical attributes that form groundwater flow within an aquifer are very heterogeneous [35]. To effectively take into consideration all these properties of groundwater resources, various groundwater management models warrant complex and highly distributed models in a time series. Previously, the tendency in groundwater resource management through distributed modelling was to increase the numerical resolution, include many physical attributes, and to enlarge the model's domain using either a finite difference approximation or a finite element method [36-39]. Although the application of either the finite element or finite difference methods to groundwater resource management has enabled real-world and complex systems to be modelled, this has led to an increase in the model's running time.

In many instances, groundwater levels are manually measured using a data logger coupled with a pressure transducer and electrical probes or a graduated steel tape dipper $[2,40]$. Although these techniques are simple and easy to use, they are prone to human error, are unreliable, and are inefficient. Since the development of super-fast-speed computers as well as user-friendly software, the field of hydrogeology has frequently used 
physical-based numerical techniques to model groundwater. However, it is difficult to define the needed information accurately because spatial data on hydrological as well as geological properties of the aquifer are needed [18]. Hence, data gathering is essential to maintaining groundwater resource management and to perform crucial water-related functions, such as mitigating against drought [40]. Likewise, many researchers have combined many physical numerical techniques such as both simulation and optimisation modelling methods to manage groundwater resources [28,41-47]. Additionally, different groundwater resource management models have been developed to minimise groundwater resource scarcity $[18,22,29,32-34,48-65]$.

Chang et al. [34], developed a numerical groundwater resource model from a conceptual model but failed to capture the computational complexities in the nature of the groundwater aquifer system while focusing only on the fundamental and main principles [34]. This is because it is difficult to formulate both groundwater flow equations and prove the hydrogeological parameters for conceptual models due to computational complexity. Additionally, there are uncertainties and difficulties in obtaining long-term series data for groundwater levels using numerical modelling processes $[32,50,66]$. Thus, making longterm series models time-consuming, laborious, unscalable, and costly [54]. However, it is important to achieve an acceptable groundwater resources model for performance efficiency. However, past information was not often available because most government agencies in charge of water often collect this data just once or twice a year during the agricultural season [64]. Additionally, the majority of traditional groundwater models are process-based [18]. This means much supplementary spatial data on the aquifer's hydrological and geological properties is mandatory. Further challenges occur in groundwater modelling due to the complexity of hydrogeology sub-surfaces as well as a spatiotemporally variability in societal pumping activities [65].

As identified in most pieces of literature, there have been many efforts developed previously to proffer solutions to groundwater modelling. Over the years, the use of machine learning as an alternative solution for the modelling of groundwater has gained more attraction [34]. In contrast with numerical models, machine learning models are data-driven and require learning from historically measured data from the aquifer system. These models do not need to comprehend the physical processes or the internal framework of an aquifer [23,67]. Other solutions such as linear and nonlinear programming techniques which are driven solely by data acquisition have also been proffered $[9,14,15,41,43,46,47,54-56,68]$. Data-driven classification models such as Genetic Programming (GP), Artificial Neutral Networks (ANNs), Fuzzy Logic, as well as Support Vector Machines (SVMs), and time-series techniques such as Autoregressive Integrated Moving Average (ARIMA) and Autoregressive Moving Average (ARMA), are proven alternatives to conceptual models $[22,29,50,51]$. However, they are not scalable enough when there is a change in dynamic groundwater levels over time as well as when available data are insufficient to give accurate results [18]. Furthermore, Husna et al. and Kenda et al. [] observed that the majority of groundwater resource management models have failed to capture computation efficiency and scalability [18,52]. Despite the huge improvements in the existing groundwater resource management models, researchers pointed out lack of efficiency and scalability as a result of considerable uncertainty, over-dependent on unavailable additional datasheets and potential substantial errors [58,69-75]. Both data-driven machine learning models and numerical techniques have been used extensively in modelling groundwater resources, however, the numerical techniques have physical limitations such as the aquifer's state as well as it having extensive physical properties qualification, being laborious, and being expensive [76]. Therefore, it is necessary to develop a model that can identify these limitations and use the information for groundwater management and policymaking [77].

In 1990, John Romkey created the first world's Internet of Things (IoT) Interop Internet Toaster device. However, the term IoT was first coined out in 1999 by Kevin Ashton [78]. This was a toasting machine that was operated from a computer system that was 
accessing the management information base using a simple network management protocol and the internet protocol [79]. Since then, over 500 million devices have been connected to the internet. Furthermore, about 20 to 30 billion IoT devices are estimated to be connected to the internet by 2021 [80]. Over the years, the concept of the IoT has been embraced in areas including smart water, smart healthcare, smart agriculture, smart climate management, and so on [81,82]. This concept of the IoT refers to a phenomenon in which there is a connection of many smart things such as sensors, mobile phones, utility devices and industrial components through networks that possess data analysis capabilities. Thus, smart sensors and pressure transducers have found their usage in groundwater resource management, using the traditional IoT architecture for continuous data acquisition, analysis, and processing. In traditional IoT architecture, the IoT data generated by the smart devices are transmitted into the remote cloud through the internet [83]. As a result of huge data transfers from IoT devices into the cloud, the traditional IoT internet architecture has become inefficient for analysing and processing the collected data [82]. This is because this computation process exerts pressure on the cloud computing linked network, thereby causing untold stress. Furthermore, as identified in most pieces of literature, the cloud is not efficient and lacks the scalability to sustain large sums of IoT data in real-time due to its communication latency and network bandwidth [81-85].

Furthermore, the use of IoT in the management of groundwater levels as well as in the development of groundwater data-driven models has been instrumental in detecting areas of groundwater resource quantity reduction. However, the sensing instruments deployed into the observation wells have a low resolution and are too indirect to be of use for local regional assessments in geodetic methods $[69,71,74,75]$. Consequently, improvements in IoT technology in combination with improved geophysical modelling and dataassimilation are needed to meet computation that is efficient and scalable for the IoT architecture needs for groundwater resource management models.

While previous surveys have solely focussed on particular groundwater issues related to mathematical modelling and simulation models, this current review seeks to provide an IoT based inclusion perspective as it relates to groundwater resources management. Therefore, this paper aims to present a review of existing groundwater resource management models and IoT-based monitoring systems.

The arrangement of this paper is as follows; Section 2 discusses the overview and organisation of groundwater-level management models. Groundwater management and IoT are presented in Section 3. Section 4 contains the conclusion and, thereafter, the references and acknowledgements. The list of all acronyms and abbreviations used in this article is given in Table 1. 
Table 1. Acronyms.

\begin{tabular}{|c|c|}
\hline Abbreviation & Description \\
\hline ANFIS & Adaptive Neuro-Fuzzy Inference System \\
\hline ANN & Artificial Neural Network \\
\hline ARIMA & Autoregressive Integrated Moving Average \\
\hline ARMA & Autoregressive Moving Average \\
\hline EEMD & Ensemble Empirical Mode Decomposition \\
\hline EMD & Empirical Mode Decomposition \\
\hline EMI & $\begin{array}{l}\text { Environmental data Management Interface tech- } \\
\text { nique }\end{array}$ \\
\hline FDMT & Finite-Difference Model Technique \\
\hline FEMT & Finite Element Modelling Technique \\
\hline FFNN & Feed-Forward Neural Networks \\
\hline GB & Gradient Boosting \\
\hline GIS & Geographic Information Systems \\
\hline GP & Genetic Programming \\
\hline GPU & Graphics Processing Unit \\
\hline GRG & Generalized Reduced Gradient \\
\hline GWFM & Groundwater Flow Model \\
\hline HEM & Hydro-Economic Model \\
\hline HYDRUS-1D & $\begin{array}{l}\text { Heat, Water, and Solute Movement Simulator in } \\
\text { One-Dimensional Variably Saturated Media }\end{array}$ \\
\hline ICT & Information and Communication Technologies \\
\hline IDE & Integrated Development Enviroment \\
\hline IGRAC's GGIS & $\begin{array}{l}\text { International Groundwater Resources Assessment } \\
\text { Centre's Global Groundwater Information Service }\end{array}$ \\
\hline IMFs & Intrinsic Mode Functions \\
\hline IoT & Internet of Things \\
\hline ISOQUAD & $\begin{array}{l}\text { Groundwater flow and Contaminants Transport } \\
\text { Simulation Model }\end{array}$ \\
\hline LCSNs & Low-Cost Wireless Sensors Networks \\
\hline LoRa & Long Range \\
\hline LR & Linear Regression \\
\hline MAR & Managed Aquifer Recharge \\
\hline MLPN & Multilayer Perception Network \\
\hline MODFLOW & $\begin{array}{c}\text { Modular Three-Dimensional Finite-Difference } \\
\text { Groundwater Flow Model }\end{array}$ \\
\hline MODPATH & Modular Particle-Tracking Post Processing Package \\
\hline MMA & Multimodel Application \\
\hline MQTT & Message Queuing Telemetry Transport server \\
\hline NLP & Non-Linear Programming \\
\hline NoSQL & No relational Structured Query Language \\
\hline PLASM & Prickett-Lonnquist Aquifer Simulation Model \\
\hline RS & Remote Sensing \\
\hline RTs & Regression Trees \\
\hline SEAWAT & $\begin{array}{c}\text { A computer program for simulation of 3-Dimen- } \\
\text { sional, Variable-Density, Transient Groundwater } \\
\text { Flow }\end{array}$ \\
\hline SDGs & Sustainable Development Goals \\
\hline SGMP & Soil and Groundwater Management Plans \\
\hline SGRA & Sequential Gradient Restoration Algorithm \\
\hline
\end{tabular}




$\begin{array}{cc}\text { SIMGRO } & \text { Simulation of Groundwater and Surface Water Lev- } \\ \text { els } \\ \text { SMO } & \text { Sequential Minimal Optimisation } \\ \text { SVAT } & \text { Soil-Vegetation-Atmosphere Modelling } \\ \text { SVM } & \text { Support Vector Machine } \\ \text { SVMs } & \text { Support Vector Machines } \\ \text { SVM-QPSO } & \text { Support Vector Machine- Quantum-Behaved Parti- } \\ \text { SWAP } & \text { cles Swarm Optimisation } \\ \text { SWMS-2D } & \text { Soil-Water-Atmosphere-Plant Package } \\ \text { UCODE } & \text { Water and Solute Movement Simulator in Two-Di- } \\ \text { WBM } & \text { mensional Variably Saturated Media } \\ \text { WebGIS } & \text { A Universal Inverse Code } \\ \text { WOFOST } & \text { Water Balance Model } \\ & \text { Web-based Geographic Information Systems } \\ & \text { World Food Studies }\end{array}$

\section{Overview and Organisation of Groundwater-Level Management Models}

This section aims to provide an overview and organisation of the groundwater-level management model hierarchy.

\subsection{Sources of Groundwater Recharge for an Aquifer}

Naturally, the main source of groundwater aquifer recharge is the rainfall from the climate. Therefore, any upset in the climate conditions, such as less-intensive rainfalls, can lead to an alteration in the quantity of recharge for an unconfined aquifer [86]. Therefore, in a groundwater aquifer system, there is an assumption that the discharge is cancelled by the recharge, hence, there is no prolonged period of shortage in storage [20]. Although, before an abstraction occurs, there may be daily occurrences of fluctuations in the groundwater's aquifer system. However, the system remains in a dynamic equilibrium state [20]. Moreover, hydrological stress on the groundwater system is a result of fluctuations between the discharge and recharge due to climatic changes [21]. The quantity of water required to recharge an aquifer is also affected as a result of an evaporation increase [87]. Consequently, the concept of water balance or budget follows the law of the conservation of mass, it delineates the condition of an aquifer in its natural balance before abstraction over a prolonged duration [21].

After an abstraction has occurred, the groundwater aquifer system can be artificially recharged via a pumped borehole. Therefore, a groundwater aquifer system is balanced by water from any of a combination of three methods. The methods are increasing recharge to the borehole via pumping, reducing storage in the aquifer, and/or decreasing the discharge from the aquifer caused via pumping $[20,88]$. During the artificial pumping of groundwater from a borehole, a capture is created. A capture principal as a result of pumping can be described as a decrease in discharge as well as an increase in the recharge of water that will not voluntarily flow into the groundwater system [89-90]. Hence, the new equilibrium or water balance will be achieved after enough capture is achieved [90].

\subsection{Overview of Groundwater Management Models}

A groundwater management model is a powerful mathematical aquifer management tool that utilises numerical methods such as linear and quadratic programming and machine learning with a combination of groundwater governing flow and transport equations to solve groundwater management problems [91-99]. Therefore, a traditional simulation model is utilised to answer 'what if' related questions while an optimisation model provides a solution to 'what is best' under the given limiting boundaries [28]. Over the years, groundwater hydrogeologists have attempted to evaluate groundwater resources using numerical simulation models. The application of numerical simulation models by 
the researchers in the field of groundwater hydrology has assisted them to increase their understanding of regional aquifers' functions within a particular facet of groundwater systems as well as testing the hypotheses [13,28,35,41,43,59,60,100]. Additionally, the modelling of real and complex groundwater systems has been made possible via the use of finite difference and finite element simulation models. Furthermore, this has enabled the idea for evaluation and conception frameworks towards the effective management of groundwater resources, including impacts of chemical contaminants and surface water interaction and its withdrawal. In a real-world groundwater resource management scenario, the ground water management problems are multi-dimensional and single objective simulation management methods are not adequate.

Although simulation as a tool is often utilised by groundwater managers, it fails to capture critical functional and physical restrictions while also sideling management goals. Therefore, the use of only the simulation method will not be able to achieve the optimal management objectives because determining the proper objective function of a groundwater system is very challenging and cannot be ignored. Consequently, a combination of simulation and optimisation management models is needed. An optimisation-based groundwater management model aims to provide a solution to a specified goal in the best possible manner within the various limiting boundaries. These limiting boundaries emanate from both the physical patterns of the groundwater system and the manager's requirements. In addition, optimisation as a simple tool employs the capabilities of both nonlinear and linear formulations to solve a given complex mathematical problem. Therefore, simulation-optimisation groundwater management models in optimisation formulation merge aquifer simulation models in exchange for certain constraints. Thus, optimisation and simulation groundwater models have been developed for various areas of utilisation, like the management of groundwater resource policies, the restoration of surface and groundwater resources, the control of aquifer flows, and aquifer simulation simultaneously [28,101-105].

\subsection{The Organisation of Groundwater Management Models}

According to SM Gorelick [100], studies on groundwater management models may be organised into two classes; groundwater hydraulic management models, and groundwater policy and allocation models. The main distinction between these classes is that the hydraulic management models are primarily concerned with the management of groundwater withdrawal rate in relation to its recharge rate known as stress within a given aquifer. Consequently, these models use both hydraulic heads and stress directly as decisionmaking variables. Two approaches, embedding and response matrix methods, are under this model class. The embedding method for the groundwater hydraulic management model uses the Finite Difference Management Technique (FDMT) element or finite element approximations as members of the constraint set of linear programming formulation. The response matrix method uses an external groundwater simulation model to formulate unit responses [100-113], The ground water policy evaluation and allocation models class may be further divided into hydraulic economic response model, linked simulation-optimization models and hierarchical models. This class can be used to perform complex economic interactions analysis and policy evaluation of surface-groundwater quota challenges [102]. This class is symbolized by the use of multiple simulations and optimization techniques. These classes are discussed extensively by Remson et al., Pinder and Bredehoeft, and Gorelick, S.M. [28,32,100,102,106,111-113]. Figure 1 shows the organisation of groundwater management models into groups. 


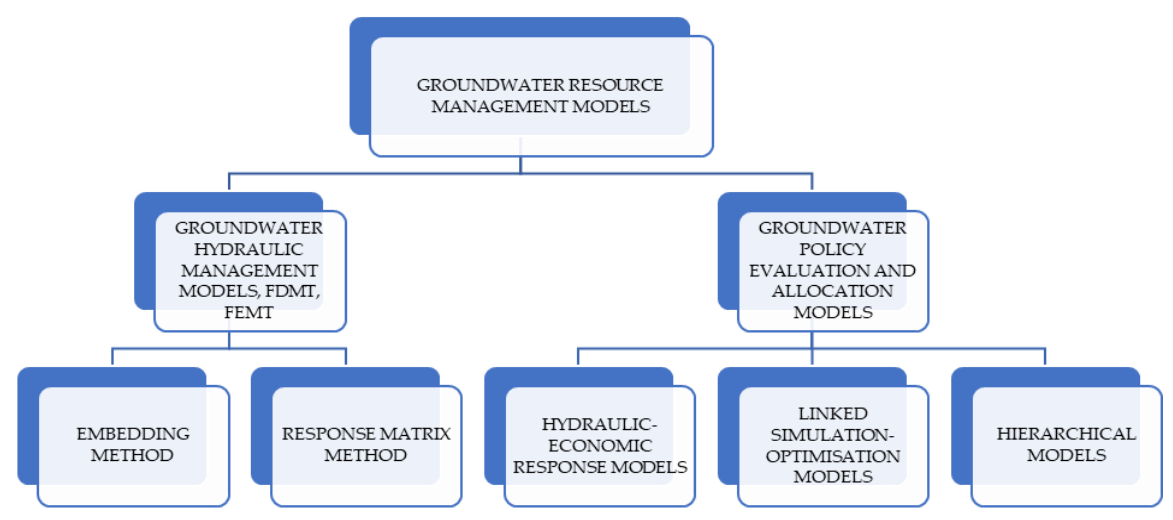

Figure 1. The classification of groundwater resource management models [100].

According to Kisi et al., studies on groundwater management models may be divided into two groups. These are the physical or process-based approach/model and datadriven-based approach [56]. The physical-based models are based on the use of the physical parameters of the groundwater bed to determine any changes in the water level. However, these models are difficult to execute, expensive, and need to be partitioned to obtain numerical information [62]. Furthermore, although groundwater management models are essential tools to examining the negative effects of human activities on the dynamic nature of groundwater resources, the physical and the hydrogeological surroundings require reliable data [107-108]. The aquifer of the physical groundwater management model's aquifer surrounding includes the topography, soil, climate, land use, agricultural practice, demand for groundwater usage, drainage, and canal ditches. Whereas the hydrogeological surrounding refers to the groundwater dynamism, the hydraulic parameters for each of the aquifer layers, aquifer system parameters, and aquifer boundary conditions. This hydrogeological surrounding varies in time and space $[49,109]$. Above all, to achieve accurate modelling results from a physical model, it is essential to have a calibration of the model using accurate data. Thus, achieving more efficient and accurate computation must be explored deeper.

Data-driven models' groups are differentiated on the objective function where the decision is based solely on groundwater hydraulic functions and the other whose management decisions are based on the evaluation of policy as well as the allocation of groundwater economy. Thus, the former is aimed at the management of groundwater stresses, like recharging and discharging, well costs, and aquifer hydraulics. These groundwater hydraulic management model groups treat both the hydraulic heads and stresses as direct management objective function decision variables. On the other hand, the groundwater policy evaluation and allocation model group aims to solve groundwater management problems by examining the complex relationship between groundwater and surface water and their economic interactions. These evaluations form the basis of regional groundwater policy [69,101-102]. The process-based/physical-based groundwater model in its primitive structure, possess four basic components; it is nonlinear concerning its decision variables; requires the solution of nonlinear partial differential equations to describe the transport as well as the flow of groundwater; it is stochastic as its primary uncertain source is associated with the aquifer simulation mode; and it is a 
mixed-integer programming decision because it contains discrete and continuous objective functions $[14,110]$. Therefore, generally these models are identified by their multiple objectives optimisation characteristics and possess robust economic management units.

In all these groups of optimisation and simulation groundwater management models, a set of different differential mathematical equations are used to describe the groundwater flow. Thus, a mathematical model is formed as a result of the combination of these different differential equations with their boundaries as well as initial conditions. The basis of groundwater modelling is governed by the combination of Darcy's law and the conservation of mass law through an anisotropic, nonhomogeneous, porous medium [111113]. The combined flow equation is represented by Equation (1):

$$
\frac{\partial}{\partial \mathrm{x}}\left(\mathrm{T}_{\mathrm{x}} \frac{\partial \mathrm{h}}{\partial \mathrm{x}}\right)+\frac{\partial}{\partial \mathrm{y}}\left(\mathrm{T}_{\mathrm{y}} \frac{\partial \mathrm{h}}{\partial \mathrm{y}}\right)+\mathrm{W}=\mathrm{S} \frac{\partial \mathrm{h}}{\partial \mathrm{x}}
$$

where $h$ is the hydraulic potential $(\mathrm{L}), x$ and $y$ are cartesian coordinates $(\mathrm{L}), T_{x}$ and $T_{y}$ are the components of the transmissivity tensor $\left(\mathrm{L}^{2} \mathrm{~T}^{-1}\right), \mathrm{W}$ is a general source/sink term $\left(\mathrm{LT}^{-1}\right)$, while $\mathrm{S}$ is the storage coefficient, and $\mathrm{t}$ is time $(\mathrm{T})$. The efficient measurement of groundwater level (head) is important to improving the model's usage. Hence, various non-linear time-series mathematical models have been proposed to measure groundwater levels in one as well as two-dimensional flow. However, many physical management model parameters should be treated in three dimensions. This three-dimensional management application method is an open method for groundwater resource management.

\subsection{Data-Driven Process-Based Management Models}

The latest machine learning data-driven classification models, such as Artificial Neural Network (ANN) technique, Genetic programming (GP), Adaptive Neuro-Fuzzy Inference System (ANFIS), and support vector machine (SVM) as well as time series methods such as Autoregressive Integrated Moving Average (ARIMA), Multiobjective Function Approach, and Autoregressive Moving Average (ARMA), are proven alternatives to the management of groundwater resources. They are treated as nonlinear standard estimators that can overcome the difficulties associated with physical models and are less costly. However, they are less accurate with insufficient availability of data and when the focus of research is not based on a physical mechanism [51]. Furthermore, there are numerical groundwater models developed from a conceptual model. However, these models often neglect complexities while focusing only on the main fundamental principles of the groundwater systems [34]. Meanwhile, finding long time-series data for a numerical model is exceedingly challenging during the modelling processes.

\subsection{Data-Driven Mathematical Models for Groundwater Resources Management}

The groundwater resources prediction model is described as a regression problem $[18,114-115]$. This means the goal is to forecast, predict, and manage any changes in groundwater resources on any particular day according to the available data. This makes the availability of accurate data important for efficient groundwater management. Thus, data-driven mathematical models use previous data based on the underlying process behind a particular phenomenon to learn the best forecast result. Therefore, the goal of this section is to provide insight into the mathematically formulation for the management of groundwater resources. Although data-driven models are discussed, they can also be used as process-based management models in order to manage groundwater resources.

\subsubsection{Sequential Gradient Restoration Algorithm (SGRA) Model}

The Sequential Gradient Restoration Algorithm (SGRA) is a dual-phase path to solving Non-Linear Programming (NLP) problems. Beginning from a feasible design point of view, the gradient phase decreases the value of the objective function while at the same time fulfilling the obligation of the linearised active constraints. This will lead to constraints violation of the nonlinear active constraints. Consequently, the restoration phase catalyses the design towards feasibility, which may produce a new as well as a distinct set 
of constraints. This process of a two-phase cycle is repeated until the optimum value is achieved [116]. This technique incorporates a decent property with each cycle. The SGRA uses an active constraint strategy just like other algorithms. This method has been favourably compared to the generalised reduced gradient (GRG) and the gradient projection method. However, in comparison, the SGRA combines the two phases [116-117].

The SGRA assumes the inequality constraints of the form by Equation (2):

$$
g_{j}(X) \geq 0 ; j=1,2, \ldots, m
$$

The general problem is defined as:

Minimise

$$
f(X),[X]_{n}
$$

Subject to:

$$
\begin{gathered}
{[h(X)]_{t}=0} \\
{[g(X)]_{m} \leq 0} \\
X^{\text {low }} \leq X \leq X^{u p}
\end{gathered}
$$

Only active inequality constraints are of interest in the SGRA. Although, equality constraints are always active. Active inequality constraints also include violated constraints. If " $\mathrm{v}$ " indicates the set of active constraints, Equations (4) and (5) can be combined into a vector of active constraints $(\Phi)$;

$$
\Phi(X)=\left[\begin{array}{c}
h(X) \\
g(X) \geq 0
\end{array}\right]_{v}
$$

The number of active inequality is $\mathrm{v}-\mathrm{l}$. The Lagrangian for the problem can be expressed in terms of the active constraints alone (since the multipliers for the $g_{f}(X)<0$ will be set to zero as part of Kuhn-Tucker (KT) conditions). In optimization, the KT conditions for a solution in NLP are described as the first optimal test derivation that must be satisfied. The KT conditions are then expressed by equations 8 to 10 .

$$
\begin{gathered}
\nabla_{X} F\left(X, \lambda^{v}\right)=\nabla_{x} f(X)+\left[\nabla_{X} \Phi\right] \lambda^{v} \\
\Phi(X)=0 \\
\lambda_{v-t} \geq 0
\end{gathered}
$$

where $\left[\nabla_{x} \Phi\right]=\left[\nabla_{x} \Phi_{1} \nabla_{x} \Phi_{2} \ldots \nabla_{x} \Phi_{v}\right] ; \lambda^{v}=\left[\begin{array}{lll}\lambda_{1} & \lambda_{2} \ldots \lambda_{v}\end{array}\right]^{\mathrm{T}}$

Gradient phase: Given a feasible design $X^{i}$, the neighbouring gradient point can be expressed as the following where $\delta f<0$ and $\delta \Phi=0$ :

$$
\tilde{X}_{g}=X^{i}+\Delta X
$$

By imposing a quadratic constraint on the displacement $\Delta K$ in Equation (9), the problem can be set up as an optimisation subproblem in which the KT conditions are determined as given in Equation (12).

$$
\Delta X=-a \nabla F_{x}\left(X^{i}, \lambda^{v}\right)=a S
$$

In this model, the search direction is directly proportional to the gradient of the Lagrangian, which is an improved and model feature. To solve the Lagrangian, the Lagrange multipliers must be computed. This is solved by solving a system of $v$ linear equations, given in Equation (13).

$$
\left[\nabla_{X} \Phi\left(X^{\mathrm{i}}\right)\right]^{\mathrm{T}} \nabla_{X} f\left(X^{i}\right)+\left[\nabla_{X} \Phi\left(X^{\mathrm{i}}\right)\right]^{\mathrm{T}}\left[\nabla_{X} \Phi\left(X^{i}\right)\right] \lambda^{v}=0
$$

Stepsize for gradient phase: The stepsize calculation is based on driving the optimality conditions in (8) to zero. Therefore, if

$$
\tilde{X}_{g}=X^{i}-\alpha \nabla F_{X}\left(X^{i}, \lambda^{v}\right) \nabla_{X} F\left(X, \lambda^{v}\right)=\nabla_{x} f(X)+\left[\nabla_{X} \Phi\right] \lambda^{v}
$$

Commented [M61]: We have replaced hyphen (-) by the minus sign (-). Please, confirm

Commented [BA2R1]: Yes, it is okay. Thank you 
The optimum $\alpha^{\wedge *}$ is solved by cubic interpolation while trying to satisfy the condition in Equation (15).

$$
\nabla_{X} F\left(\tilde{X}_{g}, \lambda^{v}\right)^{T} \nabla_{X} F\left(X^{i}, \lambda^{v}\right)=0
$$

However, an adequate step must be taken to show that this stepsize does not cause significant constraint violation. This can be ensured by capping the squared error in the constraints by a suitable upper bound which is set up as:

$$
\Phi\left(\tilde{X}_{g}\right)^{T} \Phi \tilde{X}_{g} \leq P_{\max }
$$

Furthermore, the $P_{\max }$ is related to another performance index $\mathrm{Q}$, which is the error in the optimality conditions [97]. Thus,

$$
Q=\nabla F_{X}\left(\tilde{X}_{g}, \lambda^{v}\right)^{T} \nabla F_{X}\left(X^{i}, \lambda^{v}\right)
$$

Restoration Phase: After the end of the gradient phase, it is assumed the function will have decreased but there would have been some infeasible constraints (supposing at the initial stage of the gradient phase, there was at least more than one nonlinear active constraint). In the restoration phase, a feasible solution within the neighbour would be established. This is achieved by making sure that the linearised constraints are feasible. However, before this the active constraint set has to be updated $(v)$ since the initial feasible constraints could have become infeasible and previously infeasible constraints could have become feasible as a result of the change in design caused by the gradient phase. Thus, the design vector and the changes in design for this restoration phase can be written as:

$$
\tilde{X}_{r}=\tilde{X}_{g}+\Delta \tilde{X}_{r}
$$

The change in design for this restoration phase $\Delta \widetilde{\mathrm{X}}_{\mathrm{r}}$ can be obtained as a least square error in the design changes, subject to the satisfaction of the linear constraints. Thus, Equation (19) is used to calculate this change in the design using NLP.

$$
\Delta \tilde{X}_{r}=-\nabla_{X} \Phi\left(\tilde{X}_{g}\right) \sigma^{-v}
$$

The above is valid where $\sigma^{-v}$ is the $v^{-}$vector Lagrange multiplier of the quadrantic subproblem. Furthermore, the values for the multipliers are established through the linear equation in Equation (20), where the factor $\mu$ is a user-controlled parameter to discourage large design changes.

$$
\mu \Phi\left(\tilde{X}_{g}\right)-\nabla_{X} \Phi\left(\tilde{X}_{g}\right)^{T} \nabla_{X} \Phi\left(\tilde{X}_{g}\right) \sigma^{-v}=0
$$

The Restoration phase is iteratively applied until Equation (21) is feasible, where $\varepsilon_{1}$ represent a small number.

$$
\Phi\left(\tilde{X}_{r}\right)^{T} \Phi\left(\tilde{X}_{r}\right) \leq \varepsilon_{1}
$$

After the restoration phase, the constraints are feasible, and the next cycle of the Gradient-Restoration phase can be applied again.

\subsubsection{Linear Regression}

Linear Regression (LR) is one of the oldest and most widely used groundwater management models. Therefore, LR can be defined by Equation (22) [118-119].

$$
y=X \beta+\varepsilon
$$

This is valid where $y$ is the vector of the groundwater level changes values from the observation well, $X$ is the aquifer's independent parameters such as the historic weather data in a two-row matrix, $\beta$ is the parameter of forecasting vector that is under the investigation, while $\varepsilon$ is the errors' vector. In LR, the goal of applying this model technique is to minimise the validation set errors as well as to learn the vector parameter $\beta$. Many parameter estimation model techniques are available; however, the least-squares estimation techniques are the most popular [18] 


\subsubsection{Regression Tree and Gradient Boosting}

Decision making is an important aspect of the linear regression groundwater management model [120-121]. Therefore, a decision-tree-based algorithm known as Regression Trees (RTs) was developed. RTs operate by diving each groundwater resource value into smaller subspaces that are represented by a tree leaf. Thus, the learning samples are obtainable by averaging all the samples as well as by introducing another LR model at the node. The accuracy of this model is a function of introduction ensembles of regression. In environmental data-driven modelling applications, the RTs algorithm is very important as it is easy, fast, and successfully deployable. Gradient Boosting (GB) is the most used method in various fields. This is because GB makes practical and effective use of ensemble weaker trees from the learning set to provide final predictable results. Nonetheless, it stacks them additively [122-123]. Thus, the loss function differentials are approximated in each succeeding stage. Equation (23) is an example of a loss function.

$$
L\left(y, F_{m}(x)\right)=\frac{1}{2}\left(y-F_{m}(x)\right)^{2}
$$

From (21), the true value is represented by y. $F_{m}(x)$ is the model's prediction after the $\mathrm{m}$-th stage. As stated earlier, The RTs model prediction $F_{m}(x)$ combines all the weaker tree's results.

\subsubsection{Artificial Neural Network (ANN) Model}

An artificial neural network (ANN) is a black box tool with a resemblance to a human brain's biological neural networks in certain performance characteristics which consist of an enormous equidistant distribution processing system [25,124-125]. However, FeedForward Neural Network (FFNN) models are the most commonly used and employed in modelling [32,126-127]. A normal ANN model is made up of a three-layer FFNN model with an input layer, hidden layer, and output layer as well as artificial neurons with each layer interwoven with those in the next layer known as Multilayer Perception Network (MLPN). As such, the output of a node layer determines the weight as well as the type of transform of the sole function of the input it receives from the former layer. Therefore, previous research trained the ANN with the Bayesian regularisation algorithm and tansigmoid transfer function because it performs better $[18,29,32,51]$. This is mathematically expressed by equation (24), where the input vector is $x_{i}$, the output is $y_{j}$, the bias is $b_{i}$, the weight connecting $x_{i}$ and $x_{i}$ is $x_{j i}$ the number of nodes is represented by $N$, while the activation function is $\mathrm{f}$ within the presentation layer

$$
y_{j}=f\left(\sum_{i=1}^{N} w_{j i} x_{i}+b_{j}\right)
$$

The application of ANN by many researchers has proven to be a success. The ANN time series data trained model was used successfully to predict the principal factors af fecting algal blooms in the man-made Lake Juam reservoir [128]. Furthermore, ANN models have been applied in various scenarios such as the estimation of a regional index flood in an ungauged catchment of the Chindwin River in Myanmar, to evaluate an extreme daily precipitation potential in Athens, Greece, and for river flow rate and sediment load from Rantau Panjang Station on Johor River [129-132]. The results showed that ANN models are superior to the conventional regression method. 


\subsubsection{Adaptive Neuro-Fuzzy Inference System (ANFIS) Model}

An Adaptive Neuro-Fuzzy Inference System (ANFIS) model can be described as an adaptive neural hybrid algorithm that is based on a fuzzy inference system. This model was first inaugurated in 1993 by Jang et al. [133-134]. Furthermore, ANFIS has been found to be capable of approximating any continuous and real function in a compact set to an acceptable degree of accuracy universally. In the ANFIS model, it is assumed that the fuzzy inference system has two inputs, $x$ and $y$, as well as one output $f$. Thus, it can be expressed by the set of rules in Equations (25) and (26).

$$
\begin{aligned}
& \text { Rule } 1 \text { : If } x \text { is } A_{1} \text { and } y \text { is } B_{1} \text {; then } f_{1}=p_{1} x+q_{1} y+r_{1} \\
& \text { Rule 2: If } x \text { is } A_{2} \text { and } y \text { is } B_{2} \text {; then } f_{2}=p_{2} x+q_{2} y+r_{2}
\end{aligned}
$$

This is expressed where $x$ and $y$ are the crisp inputs to the node $i$, the low, and medium or high characterised linguistic labels by the convenient membership functions are represented by $A_{i}$ and $B_{i}$. Parameters of the first-order fuzzy model are represented by $p_{i}, q_{i}$, and $r_{i}(i=1,2)$. The ANFIS models have a higher capability for modelling nonlinear dynamic hydrology and diverse water resources among all the models for effective water management. In terms of efficiency and accuracy, the ANFIS models were utilised with machine learning for the estimation of daily pan evaporation as well as long-term dam inflow water [135-137]. The result showed that the ANFIS model performed better than any traditional empirical techniques. The ANFIS model has been used for rainfallrunoff modelling, groundwater modelling, as well as evaporation modelling [32, 138140].

\subsubsection{Support Vector Machine (SVM) Model}

The support vector machine (SVM) is a machine learning approach characterised by the statistical learning principle [141-142]. Therefore, its solution is obtainable via an optimisation algorithm using a regression hyperplane. Although, in a regression SVM model, an insensitivity loss function, as well as a regression hyperplane, is a convex dual optimisation problem. In addition, the Sequential Minimal Optimisation (SMO) algorithm is often used to provide a solution to problems involving the dual optimisation of the SVM. Mathematically, the SVM deterministic function is expressed as shown in Equation (27).

$$
f(x)=w \cdot \phi(x)+b
$$

In this equation $w_{i}$ is a weight vector, while $\mathrm{b}$ is a bias, and the high-dimensional feature space $\mathrm{x}$ is mapped by a non-linear transfer function $\phi$. This SVM model has been deployed by many researchers in the field of engineering to solve hydrogeology and hydrology drawbacks. The results show that the SVM model performed better than the ANN model. Limited climatic data were used to evaluate daily evapotranspiration using the SVM model in an extremely arid region [143]. Of the four models used, the SVM model proved to be the best. Additionally, the SVM model assembled with Quantum behaved Particles Swarm Optimisation SVM-QPSO model was used to forecast streamflow every month [144]. The result shows that the SVM model ensures a high prediction degree of streamflow reliability and accuracy. In addition, several researchers applied the SVM model to predict, estimate, and evaluate the streamflow as well as the water level of Lake Van in Turkey $[66,145-147]$. The results showed that the SVM model outperformed the regression and ANN models.

\subsubsection{Empirical Mode Decomposition (EMD)}

Empirical Mode Decomposition (EMD) is a data-adaptive full algorithm technique used for analysing signals that are non-linear as well as non-stationary [148]. Thus, for EMD to perform its basic function of decomposing an original signal to a various number of intrinsic mode functions (IMFs), two conditions must be met: (a) number of extrema and zero crossings must be equal or differ at most by one, and (b) functions are symmetric 
and the mean value of the upper as well as lower envelopes should be zero. However, mode mixing has been identified as the major shortcoming of EMD's implementation [149]. Mathematically, the EMD can be obtained using Equation (28).

$$
x[x]=\sum_{k=1}^{K} I M F_{k}[n]+R[n]
$$

This equation works where the corresponding residue to the signal approximation at the lowest resolution is represented by $R[n]=m_{K}[n]$ and $I M F_{k}[n]$ is the k-th IMF. It is, however, widely claimed that the EMD, as well as the Ensemble EMD (EEMD), are computationally intensive to run. Over the past few years, both the EMD and EEMD have demonstrated higher effectiveness in comparison to the Fourier techniques. Thus, it has been extensively deployed in various disciplines such as image analysis, the health sector for diagnosis, biomedicine, and big data logging.

Table 2 shows a summary of the latest data-driven groundwater resource management methods of modelling.

Table 2. Summary of data-driven groundwater resource management modelling methods.

\begin{tabular}{cl}
\hline \multicolumn{1}{c}{ Authors } & \multicolumn{1}{c}{ Methods } \\
\hline $\begin{array}{c}\text { Valipour et al. [63- } \\
\text { 64] }\end{array}$ & $\begin{array}{l}\text { Improved Random Forest Re- } \\
\text { gression With A Combination } \\
\text { Of Random Features }\end{array}$ \\
\hline & $\begin{array}{l}\text { Canonical correlation forest } \\
\text { gorithm with a combination } \\
\text { the random features simula- }\end{array}$ \\
& $\begin{array}{l}\text { Swarm optimisation and } \\
\text { neuro-differential evolution } \\
\text { methods }\end{array}$ \\
\hline
\end{tabular}

Emamgholizadeh et Artificial Neural Network al. $[29,50-52,61] \quad($ ANN) based

Objectives Shortcoming

These authors pro- $\quad$ The effectiveness of these methods and sovide the application lutions could not be established by these auof simulation model- thors with a field experiment. This is due to ling methods in costs and time constraints, increase in comgroundwater re- putational complexity, as well as needs parsource management. titioning

These authors pro-

posed this method to The accuracy of this method is instantanesolve the problems of ous. Hence, this makes it unsuitable for data scarcity at a site groundwater resource prediction over a and low-dimensional long period. data

The objective of this method was to pro-

vide accurate predic- ANN models are prone to incur the probtions without an in- lems of local minima and overfitting. crease in costly com-

putational time. Although SVM is robust for groundwater The objective of this resource prediction, as highlighted by these

Yoon et al. Super Vector Machine Method method is to over- authors, it is sensitive to redundant and groundwater level enough and requires more time because of predictions the trial and error it requires. SVM also has high parametrisation complexity.

The objective of this This model is negatively hampered due to a model was to evalu- This model is negatively hampered due to a

Mustafa et al. Groundwater flow model and ate the effects of hu- lack of data in arid and semi-arid regions. $\begin{aligned} {[28,57,58,61,65] \text { multiobjective method } } & \begin{array}{l}\text { man activities on } \\ \text { groundwater dynam- }\end{array} \\ & \text { quality evidence-based data for it to be reli- }\end{aligned}$ ics

Kisi et al. Adaptive Neuro-Fuzzy Infer- The objective of this Although ANFIS has performance accepta$[48,56,57,61,63,140]$ ence System (ANFIS) model is to overcome bility in modelling many environmental 
challenges with both and hydrological phenomena, it has many the ANN and SVM weaknesses, such as probable entrapment at models local minima and slow convergence, making it ineffective in modelling.

With the advancements in data mining for modelling, optimisation, and simulation techniques for groundwater resources management, the use of finite difference and finite elements have increased exponentially. Although, the use of the Finite Element Modelling Technique (FEMT) was first instigated by Lee and Cheng in 1974, for seawater encroachment in a coastal aquifer [153]. Likewise, Tyson and Weber, in 1963, advocated the use of electronic computers in the simulation of the dynamic behaviour of groundwater basins using the Finite-Difference Model Technique (FDMT) [154]. Consequently, both the FEMT and FDMT have been used extensively for the Groundwater Flow Model (GWFM), Hydro-Economic Model (HEM), Calibration (C), Sensitivity Analysis, (SA), Water Balance Model (WBM), as well as Validation/Verification (V) [104]. However, the efficacy of these modelling solutions depends largely on their adequate verification. Table 3 is a summary of some of the relevant researchers that have applied these two modelling techniques in groundwater resources management [104].

Table 3. Summary of relevant application of FEMT and FDMT and their purposes.

\begin{tabular}{|c|c|c|c|c|}
\hline Study & Application/Code & $\begin{array}{l}\text { Modelling } \\
\text { Technique }\end{array}$ & Objectives & Scheme \\
\hline$[155-158]$ & $\begin{array}{ll}\bullet & \text { GWFM } \\
\bullet & \text { SWAP } \\
\bullet & \text { WOFOST } \\
\text { ] } & \text { SEBAL } \\
\bullet & \text { SLURP } \\
\bullet & \text { SWAP-SWATRE } \\
\text { - } & \text { SIMGRO }\end{array}$ & FEMT & $\begin{array}{l}\text { The authors combined these applica- } \\
\text { tions/codes with the FEMT to solve a } \\
\text { regional groundwater flow challenge. } \\
\text { The simulation result shows a better } \\
\text { performance in comparison to using } \\
\text { only MODFLOW. }\end{array}$ & $\begin{array}{ll}\text { - } & \text { Calibration } \\
\text { - } & \text { Validation/Verification } \\
\text { - } & \text { Simulation }\end{array}$ \\
\hline$[159-160]$ & $\begin{array}{ll}\text { - } & \text { MODFLOW } \\
\text { ]- } & \text { GFLOW } \\
- & \text { MODPATH }\end{array}$ & FDMT & $\begin{array}{l}\text { The objective of this method was to } \\
\text { use cross-correlation analyses on the } \\
\text { field data in order to achieve a theo- } \\
\text { retical understanding of an aquifer. }\end{array}$ & $\begin{array}{ll}- & \text { Calibration } \\
\text { - } & \text { Simulation } \\
\end{array}$ \\
\hline $\begin{array}{c}{[20,161-} \\
164]\end{array}$ & $\begin{array}{ll}\text { - } & \text { HYDRUS-1D } \\
\text { - } & \text { SWMS-2D } \\
\text { - } & \text { PLASM } \\
\text { - } & \text { MODFLOW } \\
\text { - } & \text { AQUIFEMM-1 } \\
\text { - } & \text { ISOQUAD } \\
- & \text { SVAT } \\
\text { - } & \text { SIMGRO } \\
\end{array}$ & $\begin{array}{ll}\text { - } & \text { FEMT } \\
\text { - } & \text { FDMT }\end{array}$ & $\begin{array}{l}\text { The objective was to combine the dig- } \\
\text { ital groundwater models to access } \\
\text { water and dissolved solutes in critical } \\
\text { basins and tile-drained soil aquifer } \\
\text { systems. The simulated result indi- } \\
\text { cated the possibility of simulating the } \\
\text { seasonal behaviour of the aquifer sys- } \\
\text { tem for future planning and manage- } \\
\text { ment. }\end{array}$ & $\begin{array}{ll}- & \text { Calibration } \\
\text { - } & \text { Validation/Verification } \\
& \text { Simulation } \\
\end{array}$ \\
\hline [165] & SGMP & FDMT & $\begin{array}{l}\text { The objective of this model was to } \\
\text { achieve groundwater balance analy- } \\
\text { sis of different regions. The result } \\
\text { shows that these models can be used } \\
\text { for the analysis of future groundwa- } \\
\text { ter behaviour }\end{array}$ & $\begin{array}{ll}- & \text { Calibration } \\
\text { - } & \text { Simulation } \\
\text { - } & \text { Sensitivity Analysis }\end{array}$ \\
\hline $\begin{array}{c}{[162-} \\
163,166- \\
176]\end{array}$ & $\begin{array}{ll}- & \text { MODFLOW } \\
\bullet & \text { SVAT } \\
\bullet & \text { SIMGRO } \\
- & \text { SEAWAT }\end{array}$ & FDMT & $\begin{array}{l}\text { The objective of these models is to } \\
\text { simulate the effect of water flow in } \\
\text { saturated and unsaturated zones in }\end{array}$ & $\begin{array}{ll}- & \text { Calibration } \\
- & \text { Simulation } \\
\text { - } & \text { Validation/Verification }\end{array}$ \\
\hline
\end{tabular}


- UCODE

- ISOQUAD

- $\quad$ MT-3D

- UPFLOW

- HEM

- WBM

- MMA

- GLUE

\section{the surface water in an integrated ap-}

proach. The simulated result shows

that this approach can show the ef-

fects and impacts of groundwater us-

age, drainage, and irrigation on the

evapotranspiration of various crops.

\section{Groundwater Management and Internet of Things}

This section aims to highlight the relationship and importance of the Internet of Things, which comprises Remote Sensing (RS) and Geographic Information Systems (GIS), among many other approaches [176-177], as it relates to the measurement, monitoring, management, forecasting, and modelling of groundwater resources.

\subsection{Introduction}

Effective groundwater resource management, as well as modelling, is a function of the availability of good quality data pertaining to the information of the observation well. This is because the groundwater resource measurements are the most basis supporting existence for evaluating the information of the quantity of groundwater resources stored within the aquifer [27]. The information about the aquifer's properties may include and is not limited to changes in groundwater level, storage, flow rate, and recharge as well as discharge rates. However, data are not collected automatically. Furthermore, Calderwood et al. state that the negative impact of overexploitation, as well as reduction in the recharge of groundwater resources, is often unknown, even after years have passed, due to data limitations [40]. In addition, groundwater resource information is strenuous to collect and use due to the lack of proper integration between the equipment deployed, irrelevant and inconsistent data as a result of lack of stationary large-scale flow rate hindrances, un-automated groundwater analysis processes, and a lack of interoperability in previous systems [177-182]. Consequently, these limitations are causing untold strains in groundwater resource management. Additionally, most groundwater resource management models cannot provide any reliable decisions or support without the required data input. Hence, there is a need for a contemporary, scalable, and real-time IoT-based management system solution for groundwater resources management. Therefore, via the advancements recorded in the field of Information and Communication Technologies (ICT), there are many opportunities available to manage the groundwater resource crises.

There are various ground water level monitoring systems. These systems vary in technology, monitoring, and management tasks, scalability, the solutions they render, and the cost implications. Historically, the traditional technique of measuring groundwater levels involves the use of a manual tape measure. Furthermore, there are emerging threats that the majority of groundwater level measuring networks are being regularly abandoned due to a decline in global groundwater monitoring [183-185]. Consequently, groundwater resources are often inadequately monitored, despite the fact that they are needed for calibration and the validation of groundwater resources models [185-186]. These aforementioned challenges can be solved through the use of the Internet of Things (IoTs) techniques [177].

The application and deployment of low-cost IoT-enabled Wireless Sensors Networks (WSN) technologies in surface water management have gained tremendous progress. However, the contrary is the case in groundwater-level management [187-190]. Although there are few application cases, they are synonymous with the use of high power and cost networks; most deployed are commercial pressure transducers without outlining their energy implications, power consumption analysis, or the overall cost implications [187] Consequently, the use of the Internet of Things based Low-Cost Wireless Sensors Net- 
works (LCSNs) has emerged as an alternative to solve these challenges. Contrarily, according to Mao et al. and Chan et al., the growing deployment of LCSNs in groundwater resource management has produced a limited quantity of studies with corresponding open data as well as them having failed to provide much-needed information to the water managers, scientists, and other policymakers [188-200]. Rather, non-technical issues like socio-economic contexts, operational and financial mechanisms, and stakeholder engagements, which are hindering the advantages of deploying these LCSNs, are mostly concentrated on [189]. Therefore, there is an urgent need to have a better understanding of these emerging challenges through the existence of more research papers, the development of scientific tools, as well as the assessment of possible available future opportunities for the deployment of IoT-based technologies for groundwater resources management.

\subsection{Architecture of IoT Based Groundwater Monitoring System}

Generally, the groundwater level IoT-based system architecture can be subdivided into three layers. These are the physical layers, the service layer, and the presentation layer [200-225]. In the physical layer, the communication equipment, as well as various sensor nodes for basic data acquisition of relevant groundwater level and aquifer information, are built-in. The raw data measured and collected are deployed to the service layer. At the service layer, there are various tools for data analytics. This layer also stores the received data from the physical layer. Both the application and business logic implementation are implemented at this layer, thus, making it an important part of the architecture. The presentation layer is the visualisation layer where the users are allowed to interact as well as view the displayed information on a screen monitor.

Figure 2 shows an overview and working representation of the workflow of groundwater level IoT based monitoring system. This shows the interconnection of the sensors deployed into the well, the nodes, gateway, and the end-user platform. The arrows indicate the direction of the flow of data. The solid line represents the direction of the data received, while the broken lines represent the request sent for data. In this system, the IoT is combined with the GIS to ensure the real-time uploading of groundwater level data, this improves the quality of the database and provides geographical information about the system. The sensors deployed into the observation wells acquire and send the corresponding measurements of groundwater level parameters to their nodes over the Modbus protocol employed. From the nodes, the data is sent via the Long Range (LoRa) wireless network to the gateway. The data is saved into the Message Queuing Telemetry Transport (MQTT) server platform, which is connected to the No relational Structured Query Language (NoSQL) database or any other Graphics Processing Unit (GPU) platform for realtime display. Examples of these web-based client GPUs are ArcGIS, API, Google Maps API, ThingSpeak, and WebGL [215,226-231]. 


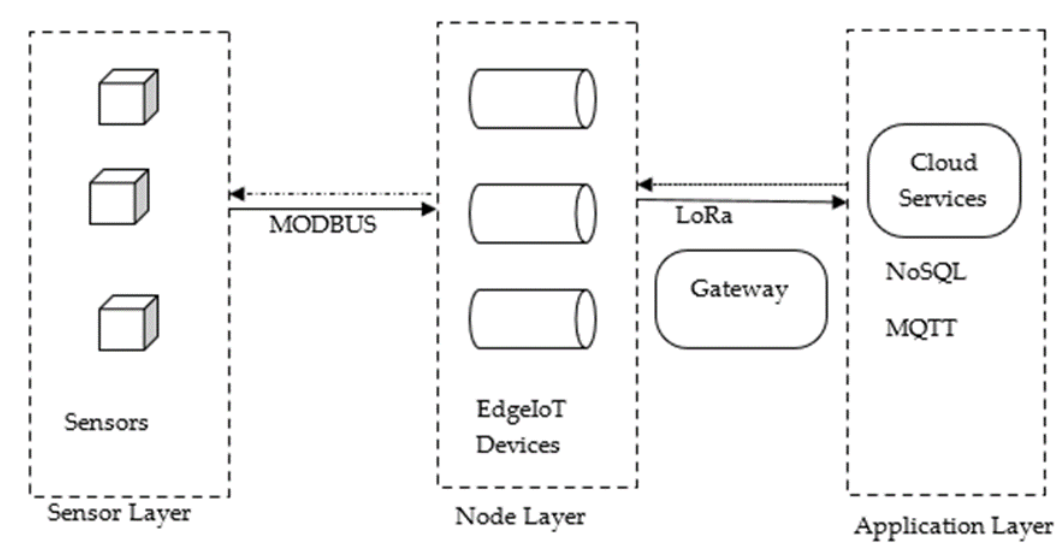

Figure 2. The architecture of Groundwater resource IoTs based monitoring system.

3.3. IoT and Groundwater Level Measurement Techniques

In recent years, the internet has changed the way human lives. Therefore, the Internet of Things (IoT) as a facet of the internet has become the ultimate layer on which several things such as smart gadgets are interconnected. This concept of the IoT has been embraced in many areas of human endeavours, including smart water and groundwaterlevel management. Thus, IoT techniques are used to collect, transfer, and analyse the required groundwater level data. The major advantage of IoT's deployment is its ability to be able to combine with several technologies, such as wireless sensors, cloud computing, ubiquitous computing, RFIP, and software [191]. Thus, groundwater level data management in an IoT environment involves the combination of smart technologies such as sensors to collect data and transmit it over a network area, with a combination of Integrated Development Environment (IDE) software into the cloud server.

Remote sensing (RS) is an example of a classical way of obtaining the much-needed hydrological data for groundwater-level measurements using the internet [192]. However, this can only provide point data. Thus, the challenge remains on how to navigate using point data alone to determine regionally distributed data. Although the RS can be used to obtain certain groundwater resources parameters, these parameters are not often useful for groundwater management modelling. Consequently, another model will be required to manipulate the acquired data into usable or verifiable data as an input in spatially distributed models [193]. Furthermore, the data acquired via the RS are prone to noise. The substantial and most relevant data for groundwater resource management modelling are the recharge and discharge information. Of these two, recharge is very crucial for the sustainability of groundwater-level management. The application of RS for groundwater level modelling was carried out by Dams et al., for mapping out impervious surface changes for hydrological modelling [194]. More researchers also applied the RS technique for the management of groundwater resources [192, 195-197]. To solve these challenges, the IoT and machine learning techniques can be employed. Apart from RS, groundwater-level management is using in situ networks in many aquifer systems around the world. However, the difference in each monitoring well depends on the technology used as well as the frequency of the measuring data [198-200]. The in situ technique assists in the management of groundwater level by estimating the changes in (groundwater) storage, providing the user's information, flow model calibration, and general up to date system information [200-202]. 
The IoT and machine learning techniques involve the acquisition, processing, transfer, and analysis of groundwater level data interconnected using intelligent nodes. This combined with the evolution of web techniques has been used in many studies in the literature. The application of the IoT for monitoring the groundwater level's daily variations and safety quality in the mining environment was carried out by Reddy et al. using sensor technologies [203]. Additionally, Neyens et al. monitored groundwater quality and quantity from a desktop using the IoT-enabled Environmental data Management Interface (EMI) technique [204]. This same technique was also applied to saltwater intrusion monitoring. A low cost IoT-based real-time groundwater resource management system which was built for monitoring a community-based network consisting of eleven wells sited in Nova Scotia, Canada [205]. Additionally, an automated low-cost sensor network for monitoring groundwater levels was designed at the South American Subbasin Groundwater Observatory (GWO), in a real-time scenario [40]. Botta et al. presented the IoTs based sensor network review for both quality and quantity measurement of water in a smart city [206]. It should be noted that with the large amount of groundwater level data collected from many deployed sensors, there comes a new challenge of how to process, store, and deal with it. This is an open research bottleneck that needs to be unravelled.

Starting from the evolution of the web technique in the year 1993, several database managers have started to develop web-based Geographic Information Systems (WebGIS) to store the collected real-time and fast data streams [207-208]. The GIS as an example of Database Management Systems (DBMS) is embedded with the topography, geology, geometry, as well as coordinate data to assist in the storage, explanation, location, and manipulation of inputs as well as the corresponding output data information [209]. Therefore, the WebGIS technique performs better in terms of user's quality of service (QoS), can be used by multiple users, providing the benefits of cost reduction, global reach, as well as cross-platform compatibility [210].

There has been exponential growth in the development of groundwater level measurement IoT based management techniques, with a combination of relevant WebGIS. The GIS software known as ARCVIEW, and the groundwater model (MODFLOW) were combined for the numerical modelling of groundwater resources by Chenini and Mammou [211]. This combination was used in the central region of Tunisia. Similarly, the combination of the Managed Aquifer Recharge (MAR) and International Groundwater Resources Assessment Centre's Global Groundwater Information Service (IGRAC's GGIS) was successfully implemented using enhanced historical data from approximately 1200 site studies in about 62 nations [212]. The results show an increase in groundwater resource storage, good recharging levels, and improved water distribution management. In Table 4 a few other existing groundwater level IoT-based management techniques are presented. Most of the highlighted studies are combined both web browser and GIS software and support multiple users as well as tasks.

Table 4. Summary of relevant existing groundwater level WebGIS technique.

\begin{tabular}{cccc}
\hline Technique & Numerical Model & Spatial Interpolation & Limitation \\
\hline $\begin{array}{c}\text { Cloud-based } \\
\text { MODFLW ArcGIS [213- }\end{array}$ & None & Several methods & $\begin{array}{c}\text { This is based on the simulation modules } \\
\text { only. This limitation does not permit exten- } \\
\text { sive interpolation due to the lack of a nu- } \\
\text { merical model. }\end{array}$ \\
$\begin{array}{c}\text { Collaborative Geographic In- } \\
\text { formation Systems (CGIS) } \\
{[177,215]}\end{array}$ & Multi hydraulic & Several methods & $\begin{array}{c}\text { It is based on the computer's Random-Ac- } \\
\text { cess Memory (RAM) size. This causes de- } \\
\text { lays or freezing up during processing. }\end{array}$ \\
\hline Delft-FEWS [216-217] & Multi hydraulic & Several methods & $\begin{array}{c}\text { It is based on the computer's Random-Ac- } \\
\text { cess Memory (RAM) size. As result of this } \\
\text { limitation, the model experiences low com- } \\
\text { putation memory during its operation. }\end{array}$ \\
\hline
\end{tabular}




\begin{tabular}{|c|c|c|c|}
\hline $\begin{array}{l}\text { FREEWAT was developed as } \\
\text { a plug in GIS desktop soft- } \\
\text { ware QGIS (QGIS Develop- } \\
\text { ment Team 2017) [218-220] }\end{array}$ & Multi hydraulic & QGIS & $\begin{array}{l}\text { The interpolation speed is based on the } \\
\text { computer's RAM. This causes a delay in op- } \\
\text { erations. }\end{array}$ \\
\hline HydroShare [221-222] & $\begin{array}{l}\text { It is based on the } \\
\text { user's developed nu- } \\
\text { merical model }\end{array}$ & $\begin{array}{l}\text { Based on the user's } \\
\text { upload }\end{array}$ & $\begin{array}{l}\text { It is based on the developed model and } \\
\text { lacks space and speed. }\end{array}$ \\
\hline Tethy [223] & $\begin{array}{l}\text { It is based on multi } \\
\text { hydraulic models }\end{array}$ & Several methods & Based on a developed model \\
\hline MAGNET [224] & $\begin{array}{l}\text { It is based on multi } \\
\text { hydraulic models }\end{array}$ & Several methods & $\begin{array}{l}\text { It is limited to a } 10,000-\text { mesh number. Any- } \\
\text { thing above this number is not possible. }\end{array}$ \\
\hline
\end{tabular}

3.4. Groundwater Quantity Monitoring System

Now, to properly manage, monitor, or model the groundwater resource, the availability of data is very crucial. Furthermore, all the data-driven machine learning techniques could only be used based on the availability of historical data. Hence, an IoT-based and online groundwater quantity monitoring system is necessary for data acquisition, timely access to processed information, to assess the impact of drought on groundwater resources, as well as to format decision-making tools and to derive novel drought indicators [230]. The application of a groundwater quantity monitoring system encompasses a large distribution network of monitoring wells with corresponding distributed monitoring sensors utilising different architecture systems [231-232]. Thus, this network of observation wells provides information about the effects of hydrologic stress on the groundwater system [27]. The conventional method of obtaining data from these monitoring wells is by visiting the site once or twice a year to manually collect said data at different times. Thus, a lot of laborious manpower, money, and time is spent to monitor the groundwater level [232]. Over the years, this conventional manual method has proven to be ineffective because the human in charge may fail to carry out the monitoring. Additionally, the method lacks real-time monitoring information which is critical for making an urgent decision by a water manager. Thus, Tauro et al. suggest that the biggest challenge in groundwater management is monitoring groundwater level and flow through diverse channels. This makes hydrological data loggers expensive. Thus, the application of IoT-based low-cost and open-source instrumentation to monitor and manage groundwater quantity systems is one of the strongly needed tools. This also allows for the adjustment and tailoring of sensors to a specific hydrological need [233].

Several studies have been carried out to examine groundwater level monitoring in a network of wells. Prinos et al. used groundwater level data to design a real-time groundwater level monitoring network and portrayal of hydrologic data in Southern Florida [234]. The researchers noticed the balance between recharge and discharge is mostly tenuous during droughts. Thus, they analysed 26 years of historical data from three groundwater aquifer systems in South Florida using regression analysis. Through their development, they were able to transmit groundwater information to the groundwater managers and the public via the created web portal in a timely fashion.

Anumalla et al. developed a groundwater monitoring system based on a network of wirelessly linked field-programmable arrays and pressure sensors in Western Nebraska aquifers in the United States of America [230]. These researchers used components such as the Data Acquisition Unit (DAU), the Data Transfer Unit (DTU), and the Data Processing Unit (DPU) to design this monitoring system. Each unit performs various functions. The DAU is responsible for collecting the data from the sensor and responds to data requests from the DTU. The DTU will transport the data from the DAU to the DPU reliably. Finally, the DPU, after gathering the data from sensors, will analyse and store the data for end-use. The system operated on the researchers' argument that timely and quick groundwater data is required to make critical decisions regarding the impact of droughts on groundwater resources. 
Two low-cost groundwater level sensors based on Plastic Optical Fibres (POF) were proposed by Esequiel Mesquita et al. In their work, they presented the operation as well as the examination of the impact of using POF sensor on the monitoring of groundwater levels [234]. This work was based on the experimental principle that there is a decrease in signal between the fibre grooves and water in comparison to air. The introduction of grooves in this work increased optical signal strength as the water level also rises as well and vice and versa. The advantages of this experiment are based in its simplicity, low cost, and suitable sensitivity.

A low-cost, low-powered, IoT enabled approach integrated with energy harvesting groundwater resource monitoring system was designed by Kombo et al. [187]. In this study, the authors developed this groundwater monitoring system to produce real-time data to aid decision making in groundwater resource management in Bandamaji station situated at Zanzibar Tanzania. The brain behind this monitoring system was the Arduino UNO ATmega328P based microcontroller platform which embed with MS5803-14BA and MB280 sensors. The advantage of this prototype lies in its ability to overcome energy barriers by inculcating an automatic energy harvesting technique. This prolonged the life span of this prototype's battery.

Calderwood et al. developed a low-cost, open-source wireless sensor network for real-time, scalable groundwater monitoring utilising cellular telemetry in the South American Subbasin groundwater observatory, located in California, USA [40]. This prototype consists of sensors for groundwater level data acquisition, cellular telemetry units that transfer the acquired data via an open-source data mining pipeline, as well as a visualisation web dashboard. Additionally, the amount of water used was estimated and managed using IoT by Robles et al. at a region in Zaragoza, Spain [188]. Through this technique, efficient water monitoring, usage, and management were achieved. Furthermore, the latest water level data was continuously received by a wireless sensor network developed by Wadekar et al. [232]. They were able to visualise and manage an urban area water usage via a smartphone. This system was able to assist the consumers to plan as well as predict their water usage. Table 5 summarises a few of the related groundwater quantity monitoring systems.

Table 5. Summary of relevant existing groundwater quantity monitoring systems.

\begin{tabular}{|c|c|c|c|}
\hline $\begin{array}{c}\text { Monitoring System and } \\
\text { Sensor Type } \\
\end{array}$ & Network Technologies & Processing Board & Limitation \\
\hline $\begin{array}{c}\text { Unidata Pressure Sensor } \\
\text { [230] }\end{array}$ & 802.11 based WLAN & $\begin{array}{l}\text { PIC12F675 microcontrol- } \\
\text { ler on Altera Nios FPGA } \\
\text { board }\end{array}$ & $\begin{array}{l}\text { The details of the power consumption } \\
\text { and energy harvesting were not re- } \\
\text { ported. However, the cost analysis was } \\
\text { reported. }\end{array}$ \\
\hline $\begin{array}{l}\text { Plastic Optical Fibres } \\
\text { Sensor [234] }\end{array}$ & $\begin{array}{l}\text { MiWiTM-P2 P wireless } \\
\text { module from Microchip } \\
\text { Technologies }\end{array}$ & $\begin{array}{l}\text { PIC24FJ256DA206 16-bit } \\
\text { microcontroller from Mi- } \\
\text { crochips Technologies }\end{array}$ & $\begin{array}{l}\text { Salty water affects its performance as } \\
\text { well as the temperature calibration not } \\
\text { being precise. The details of power con- } \\
\text { sumption analysis were not reported. }\end{array}$ \\
\hline $\begin{array}{l}\text { MS5803-02BA and NXP } \\
\text { MPX5010 DP [190] }\end{array}$ & Not Specified & $\begin{array}{l}\text { Arduino Pro Mini or } \\
\text { Nano }\end{array}$ & $\begin{array}{l}\text { Except for the reported cost analysis, the } \\
\text { power consumption analysis was not } \\
\text { given. }\end{array}$ \\
\hline $\begin{array}{l}\text { Redesigned MS58030- } \\
\text { 14BA and MBE280 [187] }\end{array}$ & LoRa and GSM & Arduino Uno or Mega & $\begin{array}{l}\text { It requires one or more gateways because } \\
\text { the single-channel gateway used limited } \\
\text { the number of nodes that can communi- } \\
\text { cate with the LoRa-enabled gateway sim- } \\
\text { ultaneously. }\end{array}$ \\
\hline $\begin{array}{l}\text { A low-cost ultrasonic } \\
\text { Sensor [235] }\end{array}$ & $\begin{array}{l}\text { Texas Instruments } \\
\text { CC1200-DK and Seme- } \\
\text { tech LoRa iM880A }\end{array}$ & $\begin{array}{l}\text { TI MSP432P\$01R 32-bit } \\
\text { ARM core M4 with } 64 \mathrm{kB} \\
\text { RAM }\end{array}$ & $\begin{array}{l}\text { Due to inertia, the piezoelectric trans- } \\
\text { ducer takes some time to build up to } \\
\text { maximum amplitude; }\end{array}$ \\
\hline
\end{tabular}


High power radios;

Water tank reservoirs.

Commercial ultrasonic sensors are inflex-

Ultrasonic Sensor [236] GSM/GPRS Arduino UNO

ible, have a short maximum distance

from the target, and there was no power saving analysis.

\section{Conclusion and Future Directions}

This review presented and discussed the existing trend in groundwater resources management. In the past, most of the existing groundwater resource management models have been combined with optimisation and simulation techniques using the appropriate mathematical programming to proffer solutions to challenges within aquifers. Consequently, the previous surveys have presented a narrow review involving simulation and optimisation management models; however, this review presented a much broader IoTenabled management perspective. This is because, for any of the management modelling of groundwater resources to be achieved, the measurement of resource data is important. However, part of the general limitations are the uncertainties, from the input parameters to the system modelling. Furthermore, despite huge research attention towards solving such problems, little research evidence exists concerning achieving computationally efficient and scalable models for groundwater resource management in real-time operations Although there are various modelling tools, as presented in this review, their field applications must be ascertained.

Furthermore, there has been an unprecedented increase in the amount of data generated by electrical sensors in the Internet of Things (IoT) over the years. The application of groundwater resource IoT-based techniques is a very useful tool in data acquisition, monitoring, and manipulation in the management of groundwater resources. This technique combined with GIS has a huge potential in the field of water management. However, IoT data are mostly processed via a computing resource situated in a data centre location far away using either the internet or cloud computing. Consequently, this has led to insecurity in the privacy of users, low latency, and scalability problems. Since the IoT large data sums are transmitted into the cloud in high volumes, it is necessary to have an efficient and scalable IoT platform to extract valuable information in real-time for groundwater resource management. Additionally, the existing groundwater management systems lack large scale applications in situ management techniques.

For future research directions, the challenges of high computational inefficiency and scalability must be addressed. This will enable the groundwater-level management model to achieve computationally efficient and scalability. Additionally, the current IoT-enabled automated data processing systems for transmitting the generated data from IoT sensors into the centralised cloud are not scalable and efficient. Therefore, there is a need to develop an alternative model for the IoT-enabled groundwater-level management model. These are open research directions that should be explored. Although this is a review of existing management models for groundwater resources, it is not all-inclusive. Thus, there is a possibility of missing some other publications because it is impractical to review them all. Therefore, these gaps could also be filled with further review publications.

Author Contributions: Conceptualization, Aderemi, B.A.,Olwal, T.O, Ndam-buki, J.M, Rwanga, S.S, methodology, Aderemi, B.A.,Olwal, T.O, Ndam-buki, J.M, Rwanga, S.S.; software, Aderemi B.A.; validation, Aderemi, B.A.,Olwal, T.O, Ndam-buki, J.M, Rwanga, S.S.; formal analysis, Aderemi, B.A..; investigation, Aderemi, B.A.,Olwal, T.O, Ndam-buki, J.M, Rwanga, S.S.; resources, Aderemi, B.A.,Olwal, T.O, Ndam-buki, J.M, Rwanga, S.S.; data curation, Aderemi, B.A.; writing-original draft preparation, Aderemi B.A.; writing-review and editing, Aderemi, B.A.,Olwal, T.O, Ndam-buki, J.M, Rwanga, S.S., Aderemi T.J., Aderemi O.O., and Barbara 
Dupont ; visualization, Aderemi B.A.; supervisions, Olwal, T.O, Ndam-buki, J.M, and Rwanga,
S.S.,; project administration, Aderemi, B.A.,Olwal, T.O, Ndam-buki, J.M, Rwanga S.S.; funding acquisition, Olwal, T.O, and Ndambuki, J.M

All authors have read and agreed to the published version of the manuscript.

Informed Consent Statement: Not Applicable.

Acknowledgments: The authors acknowledge the research supports received from the Nichea Area of Climate, Water Security and Management of the Tshwanne University of Technology, Tshwane University of Technology, Pretoria, and the Water Research Council (WRC), Pretoria, South Africa.

Conflicts of Interest: The authors declare no conflict of interest.

\section{References}

1. Rejani, R.; Jha, M.K.; Panda, S.N. Simulation-Optimization Modelling for Sustainable Groundwater Management in a Coastal Basin of Orissa, India. Water Resour. Manag. 2009, 23, 235-263.

2. Mary, X.A.; Rose, L.; Rajasekaran, K. Continuous and Remote Monitoring of Ground Water Level Measurement in a Well. Int. J. Water 2018, 12, 356-369.

3. Aziz, S.Q.; Saleh, S.M.; Omar, I.A. Essential Treatment Processes for Industrial Wastewaters and Reusing for Irrigation. Zanco J. Pure Appl. Sci. 2019, 31, 269-275.

4. Chambel, A. The Role of Groundwater in the Management of Water Resources in the World. Proc. Int. Assoc. Hydrol. Sci. 2015, $366,107$.

5. Taylor, R.; Scanlon, B.; Döll, P.; Rodell, M.; Van Beek, R.; Wada, Y.; Longuevergne, L.; Leblanc, M.; Famiglietti, J.S.; Edmunds, M.; Ground Water and Climate Change. Nat. Clim. Change 2013, 3, 322-329.

6. Yin, J.; Tsai, F.T.-C. Saltwater Scavenging Optimization under Surrogate Uncertainty for a Multi-Aquifer System. J. Hydrol. 2018 $565,698-710$.

7. Yin, J.; Tsai, F.T.-C. Steady-State Approximate Freshwater-Saltwater Interface in a Two-Horizontal-Well Scavenging System. J. Hydrol. Eng. 2019, 24, 06019008.

8. Motevalli, A.; Moradi, H.R.; Javadi, S. A Comprehensive Evaluation of Groundwater Vulnerability to Saltwater Up-Coning and Sea Water Intrusion in a Coastal Aquifer (Case Study: Ghaemshahr-Juybar Aquifer). J. Hydrol. 2018, 557, 753-773.

9. Mani, A.; Tsai, F.T.-C.; Paudel, K.P. Mixed Integer Linear Fractional Programming for Conjunctive Use of Surface Water and Groundwater. J. Water Resour. Plan. Manag. 2016, 142, 04016045.

10. Conway, B.D. Land Subsidence and Earth Fissures in South-Central and Southern Arizona, USA. Hydrogeol. J. 2016, 24, 649655.

11. Castellazzi, P.; Martel, R.; Rivera, A.; Huang, J.; Pavlic, G.; Calderhead, A.I.; Chaussard, E.; Garfias, J.; Salas, J. Groundwate Depletion in Central Mexico: Use of GRACE and inSAR to Support Water Resources Management. Water Resour. Res. 2016, 52, 5985-6003.

12. Erban, L.E.; Gorelick, S.M.; Zebker, H.A.; Fendorf, S. Release of Arsenic to Deep Groundwater in the Mekong Delta, Vietnam, Linked to Pumping-Induced Land Subsidence. Proc. Natl. Acad. Sci. USA 2013, 110, 13751-13756.

13. Yang, Y.; Song, X.F.; Zheng, F.D.; Liu, L.C.; Qiao, X.J. Simulation of Fully Coupled Finite Element Analysis of Nonlinear Hydraulic Properties in Land Subsidence Due to Groundwater Pumping. Environ. Earth Sci. 2015, 73, 4191-4199.

14. Yeh, W.W. Optimization Methods for Groundwater Modeling and Management. Hydrogeol. J. 2015, 23, 1051-1065.

15. Liu, Z.; Merwade, V.; Jafarzadegan, K. Investigating the Role of Model Structure and Surface Roughness in Generating Flood Inundation Extents Using One- and Two-Dimensional Hydraulic Models. J. Flood Risk Manag. 2019, 12, e12347.

16. Raju, K.R.S.R.; Varma, G.H.K. Knowledge-Based Real-Time Monitoring System for Aquaculture Using IoT. In Proceedings of the 2017 IEEE 7th International Advance Computing Conference (IACC), Hyderabad, India, 5-7 January 2017; pp. 318-321.

17. United Nations General Assembly. Transforming Our World: The 2030 Agenda for Sustainable Development; Resolution Adopted by the General Assembly on 25 September 2015; United Nations: New York, NY, USA, 2015.

18. Kenda, K.; Čerin, M.; Bogataj, M.; Senožetnik, M.; Klemen, K.; Pergar, P.; Laspidou, C.; Mladenić, D. Groundwater Modeling with Machine Learning Techniques: Ljubljana polje Aquifer. Proceedings 2018, 2, 697.

19. Alley, W.M.; Leake, S.A. The Journey from Safe Yield to Sustainability. Groundwater 2004, 42, 12-16.

20. Konikow, L.F.; Bredehoeft, J.D. Ground-Water Models Cannot Be Validated. Adv. Water Resour. 1992, 15, 75-83.

21. Bredehoeft, J.; Durbin, T. Groundwater Development; The Time to Full Capture Problem. Groundwater 2009, 47, $506-514$.

22. Khaki, M.; Yusoff, I.; Islami, N. Simulation of Groundwater Level through Artificial Intelligence System. Environ. Earth Sci. 2015 73, 8357-8367, https://doi.org/10.1007/s12665-014-3997-8.

23. Coppola, E.; Poulton, M.; Charles, E.; Dustman, J.; Szidarovszky, F. Application of Artificial Neural Networks to Complex Groundwater Management Problems. Nat. Resour. Res. 2003, 12, 303-320.

24. Saatsaz, M.; Chitsazan, M.; Eslamian, S.; Sulaiman, W.N.A. The Application of Groundwater Modelling to Simulate the Behaviour of Groundwater Resources in the Ramhormooz Aquifer, Iran. Int. J. Water 2011, 6, 29-42. 
25. Gong, Y.; Zhang, Y.; Lan, S.; Wang, H. A Comparative Study of Artificial Neural Networks, Support Vector Machines and Adaptive Neuro-Fuzzy Inference System for Forecasting Groundwater Levels near Lake Okeechobee, Florida. Water Resour. Manag. 2016, 30, 375-391.

26. Verma, A.; Singh, T. Prediction of Water Quality from Simple Field Parameters. Environ. Earth Sci. 2013, 69, 821-829.

27. Taylor, C.J.; Alley, W.M. Ground-Water-Level Monitoring and the Importance of Long-Term Water-Level Data (no. 1217-2002); US Geological Survey: Reston, VA, USA, 2002.

28. Singh, A. Simulation and Optimization Modeling for the Management of Groundwater Resources. II: Combined Applications. J. Irrig. Drain. Eng. 2014, 140, 04014002

29. Emamgholizadeh, S.; Moslemi, K.; Karami, G. Prediction the Groundwater Level of Bastam Plain (Iran) by Artificial Neural Network (ANN) and Adaptive Neuro-Fuzzy Inference System (ANFIS). Water Resour. Manag. 2014, 28, 5433-5446, https://doi.org/10.1007/s11269-014-0810-0.

30. Sun, S.; Zhang, C.; Yu, G. A Bayesian Network Approach to Traffic Flow Forecasting. IEEE Trans. Intell. Transp. Syst. 2006, 7, $124-132$.

31. Sun, S.; Xu, X. Variational Inference for Infinite Mixtures of Gaussian Processes with Applications to Traffic Flow Prediction. IEEE Trans. Intell. Transp. Syst. 2011, 12, 466-475.

32. Gong, Y.; Wang, Z.; Xu, G.; Zhang, Z. A Comparative Study of Groundwater Level Forecasting Using Data-Driven Models Based on Ensemble Empirical Mode Decomposition. Water 2018, 10, 730 .

33. Chang, J.; Wang, G.; Mao, T. Simulation and Prediction of Suprapermafrost Groundwater Level Variation in Response to Climate Change Using a Neural Network Model. J. Hydrol. 2015, 529, 1211-1220.

34. Chang, F.-J.; Chang, L.-C.; Huang, C.-W.; Kao, I.-F. Prediction of Monthly Regional Groundwater Levels through Hybrid SoftComputing Techniques. J. Hydrol. 2016, 541, 965-976.

35. Asher, M.J.; Croke, B.F.; Jakeman, A.J.; Peeters, L.J. A Review of Surrogate Models and Their Application to Groundwater Modeling. Water Resour. Res. 2015, 51, 5957-5973.

36. Diersch, H. FEFLOW Finite Element Subsurface Flow and Transport Simulation System Reference Manual; WASY Institute for Water Resources Planning and Systems Research: Berlin, Germany, 2005; p. 292.

37. Harbaugh, A. MODFLOW-2005, The US Geological Survey Modular Groundwater Model: The Groundwater Flow Process. In U.S. Geological Survey Technology Methods; US Geological Survey: Reston, VA, USA, 2005; Volume 6-A16, pp. 1-99.

38. Doherty, J.; Simmons, C.T. Groundwater Modelling in Decision Support: Reflections on a Unified Conceptual Framework. Hydrogeol. J. 2013, 21, 1531-1537.

39. Leube, P.; Nowak, W.; Schneider, G. Temporal Moments Revisited: Why There Is No Better Way for Physically Based Model Reduction in Time. Water Resour. Res. 2012, 48, W11527, https://doi.org/10.1029/2012WR011973.

40. Calderwood, A.J.; Pauloo, R.A.; Yoder, A.M.; Fogg, G.E. Low-Cost, Open Source Wireless Sensor Network for Real-Time, Scalable Groundwater Monitoring. Water 2020, 12, 1066.

41. Ahlfeld, D.P.; Baro-Montes, G. Solving Unconfined Groundwater Flow Management Problems with Successive Linear Programming. J. Water Resour. Plan. Manag. 2008, 134, 404-412.

42. Peralta, R.; Timani, B.; Das, R. Optimizing Safe Yield Policy Implementation. Water Resour. Manag. 2011, 25, 483-508.

43. Xu, J.; Tu, Y.; Zeng, Z. Bilevel Optimization of Regional Water Resources Allocation Problem under Fuzzy Random Environment. J. Water Resour. Plan. Manag. 2013, 139, 246-264.

44. Tsai, F.T.-C.; Katiyar, V.; Toy, D.; Goff, R.A. Conjunctive Management of Large-Scale Pressurized Water Distribution and Groundwater Systems in Semi-Arid Area with Parallel Genetic Algorithm. Water Resour. Manag. 2009, 23, 1497.

45. Ayvaz, M.; Elci, A. A Groundwater Management Tool for Solving the Pumping Cost Minimization. J. Hydrol. 2013, 478, 63-76.

46. Kifanyi, G.E.; Ndambuki, J.M.; Odai, S.N. A Quantitative Groundwater Resource Management under Uncertainty Using a Retrospective Optimization Framework. Sustainability 2017, 9, 2.

47. Li, M.; Guo, P.; Ren, C. Water Resources Management Models Based on Two-Level Linear Fractional Programming Method Under Uncertainty. J. Water Resour. Plan. Manag. 2015, 141, 05015001.

48. Fallah-Mehdipour, E.; Haddad, O.B.; Mariño, M. Prediction and Simulation of Monthly Groundwater Levels by Genetic Programming. J. Hydro-Environ. Res. 2013, 7, 253-260.

49. Fu, G.; Crosbie, R.S.; Barron, O.; Charles, S.; Dawes, W.; Shi, X.; Van Niel, T.; Li, C. Attributing Variations of Temporal and Spatial Groundwater Recharge: A Statistical Analysis of Climatic and Non-Climatic Factors. J. Hydrol. 2019, 568, 816-834.

50. He, Z; Zhang, Y.; Guo, Q.; Zhao, X. Comparative Study of Artificial Neural Networks and Wavelet Artificial Neural Networks for Groundwater Depth Data Forecasting with Various Curve Fractal Dimensions. Water Resour. Manag. 2014, 28, 5297-5317.

51. Hosseini, S.M.; Mahjouri, N. Integrating Support Vector Regression and a Geomorphologic Artificial Neural Network for Daily Rainfall-Runoff Modeling. Appl. Soft Comput. 2016, 38, 329-345.

52. Mao, X.; Shang, S.; Liu, X. Groundwater Level Predictions Using Artificial Neural Networks. Tsinghua Sci. Technol. 2002, 7, 574Mao,

53. Husna, N.-e.-a.; Bari, S.H.; Hussain, M.M.; Urrahman, M.T.; Rahman, M. Ground Water Level Prediction Using Artificial Neural Network. Int. J. Hydrol. Sci. Technol. 2016, 6, 371-381.

54. Khosravi, K.; Panahi, M.; Bui, D.T. Spatial Prediction of Groundwater Spring Potential Mapping Based on an Adaptive NeuroFuzzy Inference System and Metaheuristic Optimization. Hydrol. Earth Syst. Sci. 2018, 22, 4771-4792.

55. Kisi, O.; Azad, A.; Kashi, H.; Saeedian, A.; Hashemi, S.A.A.; Ghorbani, S. Modeling Groundwater Quality Parameters Using Hybrid Neuro-Fuzzy Methods. Water Resour. Manag. 2019, 33, 847-861. 
56. Kisi, O.; Keshavarzi, A.; Shiri, J.; Zounemat-Kermani, M.; Omran, E.-S.E. Groundwater Quality Modeling Using Neuro-Particle Swarm Optimization and Neuro-Differential Evolution Techniques. Hydrol. Res. 2017, 48, 1508-1519.

57. Moosavi, V.; Vafakhah, M.; Shirmohammadi, B.; Behnia, N. A Wavelet-ANFIS Hybrid Model for Groundwater Level Forecasting for Different Prediction Periods. Water Resour. Manag. 2013, 27, 1301-1321.

58. Mustafa, S.M.T.; Hasan, M.M.; Saha, A.K.; Rannu, R.P.; Van Uytven, E.; Willems, P.; Huysmans, M. Multi-Model Approach to Quantify Groundwater-Level Prediction Uncertainty Using an Ensemble of Global Climate Models and Multiple Abstraction Scenarios. Hydrol. Earth Syst. Sci. 2019, 23, 2279-2303.

59. Ndambuki, J.; Otieno, F.; Stroet, C.; Veling, E. Groundwater Management Under Uncertainty: A Multi-Objective Approach Water $S A$ 2000, 26, 35-42.

60. Ndambuki, J.M. Multi-Objective Groundwater Quantity Management: A Stochastic Approach. Ph.D. Thesis, , Delft University, Delft, The Netherlands, 2001.

61. Shirmohammadi, B.; Vafakhah, M.; Moosavi, V.; Moghaddamnia, A. Application of Several Data-Driven Techniques for Predicting Groundwater Level. Water Resour. Manag. 2013, 27, 419-432.

62. Taormina, R.; Chau, K.; Sethi, R. Artificial Neural Network Simulation of Hourly Groundwater Levels in a Coastal Aquifer System of the Venice Lagoon. Eng. Appl. Artif. Intell. 2015, 25, 1670-1676, https://doi.org/10.1016/j.engappai.2012.02.009.

63. Valipour, M.; Banihabib, M.E.; Behbahani, S.M.R. Comparison of the ARMA, ARIMA, and the Autoregressive Artificial Neural Network Models in Forecasting the Monthly Inflow of Dez Dam Reservoir. J. Hydrol. 2013, 476, 433-441.

64. Xuanhui, W.; Tailian, L.; Xilai, Z.; Hui, P.; Jia, X.; Bo, Z. Short-Term Prediction of Groundwater Level Using Improved Random Forest Regression with a combination of random Features. Appl. Water Sci. 2018, 8, 125, https://doi.org/10.1007/s13201-018-0742 6.

65. Yin, J.; Pham, H.V.; Tsai, F.T.-C. Multiobjective Spatial Pumping Optimization for Groundwater Management in a Multiaquifer System. J. Water Resour. Plan. Manag. 2020, 146, 04020013.

66. Yoon, H.; Jun, S.-C.; Hyun, Y.; Bae, G.-O.; Lee, K.-K. A Comparative Study of Artificial Neural Networks and Support Vector Machines for Predicting Groundwater Levels in a Coastal Aquifer. J. Hydrol. 2011, 396, 128-138, https://doi.org/10.1016/j.jhydrol.2010.11.002.

67. Huang, M.; Tian, Y. Prediction of Groundwater Level for Sustainable Water Management in an Arid Basin using Data-driven Models. In Proceedings of the International Conference on Sustainable Energy and Environmental Engineering (SEEE), Bangkok, Thailand, 18-19 December 2015.

68. Li, R.; Ou, G.; Pun, M.; Larson, L. Evaluation of Groundwater Resources in Response to Agricultural Management Scenarios in the Central Valley, California. J. Water Resour. Plan. Manag. 2018, 144, 04018078.

69. Bierkens, M.F.; Wada, Y. Non-Renewable Groundwater Use and Groundwater Depletion: A Review. Environ. Res. Lett. 2019, 14, 063002.

70. Wada, Y.; Lo, M.-H.; Yeh, P.J.-F.; Reager, J.T.; Famiglietti, J.; Wu, M.-H.L.R.-J.; Tseng, Y.-H. Fate of Water Pumped from Underground and Contributions to Sea-Level Rise. Nat. Clim. Chang. 2016, 6, 777-780.

71. Wada, Y. Modeling Groundwater Depletion at Regional and Global Scales: Present State and Future Prospects. Surv. Geophys. 2016, 37, 419-451.

72. Wada, Y.; Bierkens, M.F. Sustainability of Global Water Use: Past Reconstruction and Future Projections. Environ. Res. Lett. 2014 9, 104003.

73. Wada, Y.; Wisser, D.; Bierkens, M.F. Global Modeling of Withdrawal, Allocation and Consumptive Use of Surface Water and Groundwater Resources. Earth Syst. Dyn. Discuss. 2014, 5, 15-40.

74. Richey, A.S.; Thomas, B.F.; Lo, M.H.; Famiglietti, J.S.; Swenson, S.; Rodell, M. Uncertainty in Global Groundwater Storage Estimates in a Total Groundwater Stress Framework. Water Resour. Res. 2015, 51, 5198-5216.

75. Rodell, M.; Famiglietti, J.S.; Wiese, D.N.; Reager, J.T.; Beaudoing, H.K.; Landerer, F.W.; Lo, M.-H. Emerging Trends in Global Freshwater Availability. Nature 2018, 557, 651; Erratum in Nature 2019, 565, E7.

76. Zhao, W.G.; Wang, H.; Wang, Z.J. Groundwater Level Forecasting Based on Support Vector Machine. In Applied Mechanics and Materials; Trans Tech Publications: Freienbach, Switzerland, 2011; Volume 44, pp. 1365-1369.

77. Sahoo, S.; Russo, T.; Elliott, J.; Foster, I. Machine Learning Algorithms for Modeling Groundwater Level Changes in Agricultural Regions of the US. Water Resour. Res. 2017, 53, 3878-3895.

78. Lueth, K.L. Why the Internet of Things is called the Internet of Things: Definition, History, Disambiguation. IoT Anal. 2014, 19. Available online: https://iot-analytics.com/internet-of-things-definition/ (accessed on 30 June 2021).

79. Romkey, J. Toast of the IoT: The 1990 Interop Internet Toaster. IEEE Consum. Electron. Mag. 2016, 6, 116-119.

80. Maayan, G.D. The IoT Rundown for 2020: Stats, Risks, and Solutions. Secur. Today 2020, 13. Available online: https://securitytoday.com/articles/2020/01/13/the-iot-rundown-for-2020.aspx (accessed on 1 July 2021)

81. Premsankar, G.; di Francesco, M.; Taleb, T. Edge Computing for the Internet of Things: A Case Study. IEEE Internet Things J. 2018, 5, 1275-1284.

82. Li, H.; Ota, K.; Dong, M. Learning IoT in Edge: Deep Learning for the Internet of Things with Edge Computing. IEEE Netw. 2018, 32, 96-101.

83. Sun, X: Ansari, N. EdgeIoT: Mobile Edge Computing for the Internet of Things. IEEE Commun. Mag. 2016, 54, 22-29.

84. Kaur, N.; Sood, S.K. An Energy-Efficient Architecture for the Internet of Things (IoT). IEEE Syst. J. 2015, 11, 796-805.

85. Corcoran, P.; Datta, S.K. Mobile-Edge Computing and the Internet of Things for Consumers: Extending Cloud Computing and Services to the Edge of the Network. IEEE Consum. Electron. Mag. 2016, 5, 73-74. 
86. Wu, W.-Y.; Lo, M.-H.; Wada, Y.; Famiglietti, J.S.; Reager, J.T.; Yeh, P.J.-F.; Ducharne, A.; Yang, Z.-L. Divergent Effects of Climate Change on Future Groundwater Availability in Key Mid-Latitude Aquifers. Nat. Commun. 2020, 11, 3710.

87. Portmann, F.T.; Döll, P.; Eisner, S.; Flörke, M. Impact of Climate Change on Renewable Groundwater Resources: Assessing the Benefits of Avoided Greenhouse Gas Emissions Using Selected CMIP5 Climate Projections. Environ. Res. Lett. 2013, 8, 024023.

88. Konikow, L.; Bredehoeft, J. Groundwater Resource Development Effects and Sustainability; The Groundwater Project: Guelph, ON Canada, 2020.

89. Seyler, H.; Witthüser, K.; Holland, M. The Capture Principle Approach to Sustainable Groundwater Use Incorporating Sustainability Indicators and Decision Framework for Sustainable Groundwater Use; Water Research Commission: Pretoria, South Africa, 2016.

90. Van der Gun, J.; Lipponen, A. Reconciling Groundwater Storage Depletion due to Pumping with Sustainability. Sustainability 2010, 2, 3418-3435.

91. Eltarabily, M.G.; Negm, A.M.; Yoshimura, C.; Saavedra, O.C. Modeling the Impact of Nitrate Fertilizers on Groundwater Quality in the Southern Part of the Nile Delta, Egypt. Water Supply 2017, 17, 561-570.

92. Gorelick, S.M.; Voss, C.I.; Gill, P.E.; Murray, W.; Saunders, M.A.; Wright, M.H. Aquifer Reclamation Design: The Use of Contaminant Transport Simulation Combined with Nonlinear Programing. Water Resour. Res. 1984, 20, 415-427.

93. Gordon, E.; Shamir, U.; Bensabat, J. Optimal Management of a Regional Aquifer under Salinization Conditions. Water Resour. Res. 2000, 36, 3193-3203

94. Heydari, F.; Saghafian, B.; Delavar, M. Coupled Quantity-Quality Simulation-Optimization Model for Conjunctive SurfaceGroundwater Use. Water Resour. Manag. 2016, 30, 4381-4397.

95. Izady, A.; Davary, K.; Alizadeh, A.; Ziaei, A.N.; Akhavan, S.; Alipoor, A.; Joodavi, A.; Brusseau, M.L. Groundwater Conceptualization and Modeling Using Distributed SWAT-Based Recharge for the Semi-Arid Agricultural Neishaboor Plain, Iran. Hydrogeol. J. 2015, 23, 47-68.

96. Ayvaz, M.T. Application of Harmony Search Algorithm to the Solution of Groundwater Management Models. Adv. Water Re sour. 2009, 32, 916-924.

97. Ayvaz, M.T.; Karahan, H. A Simulation/Optimization Model for the Identification of Unknown Groundwater Well Locations and Pumping Rates. J. Hydrol. 2008, 357, 76-92.

98. Coello, C.A.C.; Pulido, G.T.; Lechuga, M.S. Handling Multiple Objectives with Particle Swarm Optimization. IEEE Trans. Evol. Comput. 2004, 8, 256-279.

99. El-Ghandour, H.A.; Elbeltagi, E. Optimal Groundwater Management Using Multiobjective Particle Swarm with a New Evolution Strategy. J. Hydrol. Eng. 2014, 19, 1141-1149.

100. Gorelick, S.M. A Review of Distributed Parameter Groundwater Management Modeling Methods. Water Resour. Res. 1983, 19, 305-319.

101. Bredehoeft, J.D.; Reichard, E.G.; Gorelick, S.M. If It Works, Don't Fix It: Benefits from Regional Ground-Water Management. In Groundwater Models for Resources Analysis and Management; CRC Press: Boca Raton, FL, USA, 1995; pp. 103-124.

102. Wagner, B.J. Recent Advances in Simulation-Optimization Groundwater Management Modeling. Rev. Geophys. 1995, 33, 10211028.

103. Singh, A. Simulation and Optimization Modeling for the Management of Groundwater Resources. I: Distinct Applications. J. Irrig. Drain. Eng. 2014, 140, 04013021.

104. Singh, A. Groundwater Resources Management through the Applications of Simulation Modeling: A Review. Sci. Total Environ. 2014, 499, 414-423.

105. Gorelick, S.M. Large Scale Nonlinear Deterministic and Stochastic Optimization: Formulations Involving Simulation of Subsurface Contamination. Math. Program. 1990, 48, 19-39.

106. Velasco-Levy, A.; Gómez, S. Sequential Gradient-Restoration Algorithm for the Optimization of a Nonlinear Constrained Function. J. Astronaut. Sci. 1982, 30, 131-142.

107. Dawoud, M.A.; Darwish, M.M.; El-Kady, M.M. GIS-Based Groundwater Management Model for Western Nile Delta. Water Resour. Manag. 2005, 19, 585-604.

108. Mylopoulos, N.; Mylopoulos, Y.; Tolikas, D.; Veranis, N. Groundwater Modeling and Management in a Complex Lake-Aquifer System. Water Resour. Manag. 2007, 21, 469-494.

109. Xu, X.; Huang, G.; Qu, Z.; Pereira, L.S. Using MODFLOW and GIS to Assess Changes in Groundwater Dynamics in Response to Water Saving Measures in Irrigation Districts of the Upper Yellow River Basin. Water Resour. Manag. 2011, 25, 2035-2059.

110. Rajabi, M.M.; Ketabchi, H. Uncertainty-Based Simulation-Optimization Using Gaussian Process Emulation: Application to Coastal Groundwater Management. J. Hydrol. 2017, 555, 518-534.

111. Cooper, H.H., Jr. The Equation of Groundwater Flow in Fixed and Deforming Coordinates. J. Geophys. Res. 1966, 71, 4785-4790

112. Remson, I.; Hornberger, G.M.; Molz, F.J. Numerical Methods in Subsurface Hydrology; Wiley: Hoboken, NJ, USA, 1971.

113. Pinder, G.F.; Bredehoeft, J. Application of the Digital Computer for Aquifer Evaluation. Water Resour. Res. 1968, 4, $1069-1093$.

114. Rahmati, O.; Choubin, B.; Fathabadi, A.; Coulon, F.; Soltani, E.; Shahabi, H.; Mollaefar, E.; Tiefenbacher, J.; Cipullo, S.; Bin Ahmad, B.; et al. Predicting Uncertainty of Machine Learning Models for Modelling Nitrate Pollution of Groundwater Using Quantile Regression and UNEEC Methods. Sci. Total Environ. 2019, 688, 855-866.

115. Barzegar, R.; Moghaddam, A.A.; Deo, R.; Fijani, E.; Tziritis, E. Mapping Groundwater Contamination Risk of Multiple Aquifers Using Multi-Model Ensemble of Machine Learning Algorithms. Sci. Total Environ. 2018, 621, 697-712.

116. Venkataraman, P. Applied Optimization with MATLAB Programming; John Wiley \& Sons: Hoboken, NJ, USA, 2009. 
117. Rosen, J. The Gradient Projection Method for Nonlinear Programming. Part II. Nonlinear Constraints. J. Soc. Ind. Appl. Math. 1961, 9, 514-532.

118. Hastie, T.; Tibshirani, R.; Friedman, J. The Elements of Statistical Learning: Data Mining, Inference, and Prediction, 2nd ed.; Springer Science \& Business Media: New York, NY, USA, 2017.

119. John Lu Z.Q. The Elements of Statistical Learning: Data Mining, Inference, And Prediction. J. R. Stat. Soc.: Series A (Stat. in Soc.) 2010, 173, 693-694.

120. Breiman, L. Random Forests; TR567; UC Berkeley: Berkeley, CA, USA, 1999.

121. Cutler, A.; Cutler, D.R.; Stevens, J.R. Random Forests. In Ensemble Machine Learning; Springer: Berlin/Heidelberg, Germany, 2012; pp. 157-175.

122. Zhang, T. Sequential Greedy Approximation for Certain Convex Optimization Problems. IEEE Trans. Inf. Theory 2003, 49, 682691.

123. Friedman, J.H. Greedy Function Approximation: A Gradient Boosting Machine. Ann. Stat. 2001, 29, pp. 1189-1232.

124. Haykin, S. Neural Networks, a Comprehensive Foundation; Prentice-Hall: Upper Saddle River, NJ, USA, 1999; pp. 161-175.

125. Samarasinghe, S. Neural Networks for Applied Sciences and Engineering: From Fundamentals to Complex Pattern Recognition; Auerbach Publications: Boca Raton, FL, USA, 2006.

126. ASCE. Artificial Neural Networks in Hydrology. I: Preliminary Concepts. J. Hydrol. Eng. 2000, 5, 115-123.

127. ASCE. Artificial Neural Networks in Hydrology. II: Hydrologic Applications. J. Hydrol. Eng. 2000, 5, 124-137.

128. Cho, S.; Lim, B.; Jung, J.; Kim, S.; Chae, H.; Park, J.; Park, S.; Park, J.K. Factors Affecting Algal Blooms in a Man-made Lake and Prediction using an Artificial Neural Network. Measurement 2014, 53, 224-233.

129. Latt, Z.Z.; Wittenberg, H.; Urban, B. Clustering Hydrological Homogeneous Regions and Neural Network Based Index Flood Estimation for Ungauged Catchments: An Example of the Chindwin River in Myanmar. Water Resour. Manag. 2015, $29,913-928$.

130. Nastos, P.; Paliatsos, A.; Koukouletsos, K.; Larissi, I.; Moustris, K. Artificial Neural Networks Modeling for Forecasting the Maximum Daily Total Precipitation at Athens, Greece. Atmos. Res. 2014, 144, 141-150.

131. Afan, H.A.; El-Shafie, A.; Yaseen, Z.M.; Hameed, M.M.; Mohtar, W.H.M.W.; Hussain, A. ANN Based Sediment Prediction Model Utilizing Different Input Scenarios. Water Resour. Manag. 2015, 29, 1231-1245.

132. He, Z.; Wen, X.; Liu, H.; Du, J. A Comparative Study of Artificial Neural Network, Adaptive Neuro-Fuzzy Inference System and Support Vector Machine for Forecasting River Flow in the Semiarid Mountain Region. J. Hydrol. 2014, 509, 379-386.

133. Jang, J.-S. ANFIS: Adaptive-Network-Based Fuzzy Inference System. IEEE Trans. Syst. Man Cybern. 1993, 23, $665-685$.

134. Jang, J.-S.R.; Sun, C.-T.; Mizutani, E. Neuro-Fuzzy and Soft Computing-A Computational Approach to Learning and Machine Intelligence. In IEEE Transactions on Automatic Control; Prentice-Hall: Hoboken, NJ, USA, 1997; Volume 42, pp. 1482-1484.

135. Goyal, M.K.; Bharti, B.; Quilty, J.; Adamowski, J.; Pandey, A. Modeling of Daily Pan Evaporation in Sub Tropical Climates Using ANN, LS-SVR, Fuzzy Logic, and ANFIS. Expert Syst. Appl. 2014, 41, 5267-5276.

136. Awan, J.A.; Bae, D.-H. Improving ANFIS Based Model for Long-Term Dam Inflow Prediction by Incorporating Monthly Rainfall Forecasts. Water Resour. Manag. 2014, 28, 1185-1199.

137. Hipni, A.; El-shafie, A.; Najah, A.; Karim, O.A.; Hussain, A.; Mukhlisin, M. Daily Forecasting of Dam Water Levels: Comparing A Support Vector Machine (SVM) Model with Adaptive Neuro-Fuzzy Inference System (ANFIS). Water Resour. Manag. 2013, $27,3803-3823$.

138. Vernieuwe, H.; Georgieva, O.; de Baets, B.; Pauwels, V.R.; Verhoest, N.E.; de Troch, F.P. Comparison of Data-Driven TakagiSugeno Models of Rainfall-Discharge Dynamics. J. Hydrol. 2005, 302, 173-186.

139. Moghaddamnia, A.; Gousheh, M.G.; Piri, J.; Amin, S.; Han, D. Evaporation Estimation Using Artificial Neural Networks and Adaptive Neuro-Fuzzy Inference System Techniques. Adv. Water Resour. 2009, 32, 88-97.

140. Shiri, J.; Kişi, Ö. Comparison of Genetic Programming with Neuro-Fuzzy Systems for Predicting Short-Term Water Table Depth Fluctuations. Comput. Geosci. 2011, 37, 1692-1701.

141. Vapnik, V.N. The Nature of Statistical Learning (Theory); Springer: New York, NY, USA, 1995.

142. Vapnik, V. Statistical Learning Theory Biology, 2nd ed.; Wiley: New York, NY, USA, 1998; p. 624.

143. Wen, X.; Si, J.; He, Z.; Wu, J.; Shao, H.; Yu, H. Support-Vector-Machine-Based Models for Modeling Daily Reference Evapotranspiration with Limited Climatic Data in Extreme Arid Regions. Water Resour. Manag. 2015, 29, 3195-3209.

144. Ch, S.; Anand, N.; Panigrahi, B.K.; Mathur, S. Streamflow Forecasting by SVM with Quantum Behaved Particle Swarm Optimization. Neurocomputing 2013, 101, 18-23.

145. Çimen, M.; Kisi, O. Comparison of Two Different Data-Driven Techniques in Modeling Lake Level Fluctuations in Turkey. J. Hydrol. 2009, 378, 253-262.

146. Noori, R.; Karbassi, A.R.; Moghaddamnia, A.; Han, D.; Zokaei-Ashtiani, M.H.; Farokhnia, A.; Gousheh, M.G. Assessment of Input Variables Determination on the SVM Model Performance Using PCA, Gamma Test, and Forward Selection Techniques for Monthly Stream Flow Prediction. J. Hydrol. 2011, 401, 177-189.

147. Tabari, H.; Kisi, O.; Ezani, A.; Talaee, P.H. SVM, ANFIS, Regression and Climate Based Models for Reference Evapotranspiration Modeling Using Limited Climatic Data in a Semi-Arid Highland Environment. J. Hydrol. 2012, 444, 78-89.

148. Wang, Y.-H.; Yeh, C.-H.; Young, H.-W.V.; Hu, K.; Lo, M.-T. On the Computational Complexity of the Empirical Mode Decomposition Algorithm. Phys. A Stat. Mech. Appl. 2014, 400, 159-167.

149. Humeau-Heurtier, A.; Abraham, P.; Mahé, G. Analysis of Laser Speckle Contrast Images Variability Using a Novel Empirical Mode Decomposition: Comparison of Results with Laser Doppler Flowmetry Signals Variability. IEEE Trans. Med. Imaging 2015, 34, 618-627. 
150. Raghavendra, N.; Deka, P. Support Vector Machine Applications in the Field of Hydrology: A Review. Appl. Soft Comput. 2014, 19, 372-386, https://doi.org/10.1016/j.asoc.2014.02.002.

151. Yoon, H.; Hyun, Y.; Ha, K.; Lee, K.-K.; Kim, G.-B. A Method to Improve the Stability and Accuracy of ANN and SVM Based Time Series Models for Long-Term Groundwater Level Predictions. Comput. Geosci. 2016, 90, 144-155, https://doi.org/10.1016/j.cageo.2016.03.002.

152. Wu, Z.; Huang, N.E. Ensemble Empirical Mode Decomposition: A Noise-Assisted Data Analysis Method. Adv. Adapt. Data Anal. 2009, 1, 1-41.

153. Lee, C.H.; Cheng, R.T.S. On Seawater Encroachment in Coastal Aquifers. Water Resour. Res. 1974, 10, 1039-1043.

154. Tyson, H.N.; Weber, E.M. Use of Electronic Computer in the Simulation of Dynamic Behaviour of Groundwater Basin. In Proceedings of the ASCE Water Resources Engineering Conference, Milwaukee, WI, USA, 15 May 1963.

155. D'Urso, G.; Menenti, M.; Santini, A. Regional Application of One-Dimensional Water Flow Models for Irrigation Management Agric. Water Manag. 1999, 40, 291-302.

156. Kite, G.W.; Droogers, P. Comparing Estimates of Actual Evapotranspiration from Satellites, Hydrological Models, and Field Data: A Case Study from Western Turkey; IWMI: Anand, India, 2000.

157. Van Dam, J.; Singh, R.; Bessembinder, J.J.E.; Leffelaar, P.A.; Bastiaanssen, W.G.M.; Jhorar, R.K.; Kroes, J.G.; Droogers, P. Assessing Options to Increase Water Productivity in Irrigated River Basins Using Remote Sensing and Modelling Tools. Water Resour. Dev. 2006, 22, 115-133.

158. Hassan, A.E. Validation of Numerical Ground Water Models Used To Guide Decision Making. Groundwater 2004, 42, 277-290.

159. Pint, C.D.; Hunt, R.J.; Anderson, M.P. Flowpath Delineation and Groundwater Age, Allequash Basin, Wisconsin. Groundwater 2003, 41, 895-902.

160. Budge, T.J.; Sharp, J.M., Jr. Modeling the Usefulness of Spatial Correlation Analysis on Karst Systems. Groundwater 2009, 47, 427-437.

161. Zhu, Y.; Shi, L.; Yang, J.; Wu, J.; Mao, D. Coupling Methodology and Application of a Fully Integrated Model for Contaminant Transport in the Subsurface System. J. Hydrol. 2013, 501, 56-72.

162. Van Walsum, P.; Veldhuizen, A. Integration of Models Using Shared State Variables: Implementation in the Regional Hydrologic Modelling System SIMGRO. J. Hydrol. 2011, 409, 363-370.

163. Yang, Z.; Lu, W.; Long, Y.; Li, P. Application and Comparison of Two Prediction Models for Groundwater Levels: A Case Study in Western Jilin Province, China. J. Arid Environ. 2009, 73, 487-492.

164. Anderson, M.P.; Woessner, W.W.; Hunt, R.J. Applied Groundwater Modeling: Simulation of Flow and Advective Transport; Academic Press: Cambridge, MA, USA, 2015.

165. Singh, A.; Panda, S.N. Optimization and Simulation Modelling for Managing the Problems of Water Resources. Water Resour. Manag. 2013, 27, 3421-3431.

166. Poeter, E.P.; Hill, M.C. Inverse Models: A Necessary Next Step in Groundwater Modeling. Groundwater 1997, 35, 250-260

167. Poeter, E. All Models Are Wrong, How Do We Know Which Are Useful. Groundwater 2007, 45, 390-391.

168. Michael, H.A.; Voss, C.I. Evaluation of the Sustainability of Deep Groundwater as an Arsenic-Safe Resource in the Bengal Basin. Proc. Natl. Acad. Sci. USA 2008, 105, 8531-8536.

169. Zhang, L.; Potter, N.; Hickel, K.; Zhang, Y.; Shao, Q. Water Balance Modeling over Variable Time Scales Based on the Budyko Framework-Model Development and Testing. J. Hydrol. 2008, 360, 117-131.

170. Harou, J.J.; Pulido-Velazquez, M.; Rosenberg, D.E.; Medellín-Azuara, J.; Lund, J.R.; Howitt, R.E. Hydro-Economic Models: Concepts, Design, Applications, and Future Prospects. J. Hydrol. 2009, 375, 627-643.

171. Raes, D. UPFLOW Water Movement in a Soil Profile from a Shallow Water Table to the Topsoil (Capillary Rise); Reference Manual Department of Land Management: Leuven, Belgium, 2009.

172. Wondzell, S.M.; LaNier, J.; Haggerty, R. Evaluation of Alternative Groundwater Flow Models for Simulating Hyporheic Exchange in a Small Mountain Stream. J. Hydrol. 2009, 364, 142-151.

173. Wondzell, S.M.; Gooseff, M.N.; McGlynn, B.L. An Analysis of Alternative Conceptual Models Relating Hyporheic Exchange Flow to Diel Fluctuations in Discharge During Baseflow Recession. Hydrol. Process. 2010, 24, 686-694.

174. Yang, C.-C.; Chang, L.-C.; Chen, C.-S.; Yeh, M.-S. Multi-Objective Planning for Conjunctive Use of Surface and Subsurface Water Using Genetic Algorithm and Dynamics Programming. Water Resour. Manag. 2009, 23, 417-437.

175. Sanford, W.E.; Pope, J.P. Current Challenges Using Models to Forecast Seawater Intrusion: Lessons from the Eastern Shore of Virginia, USA. Hydrogeol. J. 2010, 18, 73-93.

176. Sherif, M.; Kacimov, A.; Javadi, A.; Ebraheem, A.A. Modeling Groundwater Flow and Seawater Intrusion in the Coastal Aquifer Of Wadi Ham, UAE. Water Resour. Manag. 2012, 26, 751-774.

177. Su, Y.-S.; Ni, C.-F.; Li, W.-C.; Lee, I.-H.; Lin, C.-P. Applying Deep Learning Algorithms to Enhance Simulations of Large-Scale Groundwater Flow in IoTs. Appl. Soft Comput. 2020, 92, 106298.

178. Narendran, S.; Pradeep, P.; Ramesh, M.V. An Internet of Things (IoT) based Sustainable Water Management. In Proceedings of the 2017 IEEE Global Humanitarian Technology Conference (GHTC), San Jose, CA, USA, 19-22 October 2017; pp. 1-6.

179. Manguinhas, H.; Martins, B.; Borbinha, J.; Siabato, W. A Geo-Temporal Web Gazetteer Service Integrating Data from Multiple Sources. In Proceedings of the 3rd IEEE International Conference on Digital Information Management, London, UK, 13-16 November 2008.

180. Talari, S.; Shafie-Khah, M.; Siano, P.; Loia, V.; Tommasetti, A.; Catalão, J.P. A Review of Smart Cities Based on the Internet of Things Concept. Energies 2017, 10, 421. 
181. Jones, W.R.; Spence, M.J.; Bowman, A.W.; Evers, L.; Molinari, D.A. GWSDAT-GroundWater Spatiotemporal Data Analysis Tool. arXiv 2014, arXiv:1310.8158.

182. Laraichi, S.; Hammani, A.; Bouignane, A. Data Integration as the Key to Building a Decision Support System for Groundwater Management: Case of Saiss Aquifers, Morocco. Groundw. Sustain. Dev. 2016, 2, 7-15.

183. Van der Gun, J. Data, Information, Knowledge and Diagnostics on Groundwater. In Advances in Groundwater Governance; CRC Press: Boca Raton, FL, USA, 2018; pp. 193-213.

184. IGRAC. Groundwater in a Changing World; IGRAC Strategy 2019-23; IGRAC: Delft, The Netherlands, 2019. Available online: https://www.un-igrac.org/resource/igrac-strategy-2019-23-groundwater-changing-world Accessed on 7 July 2020

185. Famiglietti, J.S. The Global Groundwater Crisis. Nat. Clim. Change 2014, 4, 945-948.

186. Famiglietti, J.; Cazenave, A.; Eicker, A.; Reager, J.; Rodell, M.; Velicogna, I. Satellites Provide the Big Picture. Science 2015, 349, 684-685.

187. Kombo, O.H.; Kumaran, S.; Bovim, A. Design and Application of a Low-cost, Low-Power, LoRa-GSM, IoT Enabled System for Monitoring of Groundwater Resources with Energy Harvesting Integration. IEEE Access 2021, 9, 128417-128433.

188. Robles, T.; Alcarria, R.; de Andrés, D.M.; de la Cruz, M.N.; Calero, R.; Iglesias, S.; Lopez, M. An IoT Based Reference Architecture for Smart Water Management Processes. J. Wirel. Mob. Netw. Ubiquitous Comput. Dependable Appl. 2015, 6, 4-23.

189. Mao, F.; Khamis, K.; Krause, S.; Clark, J.; Hannah, D.M. Low-Cost Environmental Sensor Networks: Recent Advances and Future Directions. Front. Earth Sci. 2019, 7, 221, https://doi.org/10.3389/feart.2019.00221. (In English)

190. Chan, K.; Schillereff, D.N.; Baas, A.C.; A Chadwick, M.; Main, B.; Mulligan, M.; O'Shea, F.T.; Pearce, R.; EL Smith, T.; van Soesbergen, A.; et al. Low-Cost Electronic Sensors for Environmental Research: Pitfalls and Opportunities. Prog. Phys. Geogr. Earth Environ. 2021, 45, 305-338.

191. Vijayakumar, N.; Ramya, R. The Real-Time Monitoring of Water Quality in IoT Environment. In Proceedings of the 2015 International Conference on Innovations in Information, Embedded and Communication Systems (ICIIECS), Coimbatore, India, 1920 March 2015; pp. 1-5.

192. Brunner, P.; Franssen, H.-J.H.; Kgotlhang, L.; Bauer-Gottwein, P.; Kinzelbach, W. How Can Remote Sensing Contribute in Groundwater Modeling? Hydrogeol. J. 2007, 15, 5-18.

193. Kemna, A.; Vanderborght, J.; Kulessa, B.; Vereecken, H. Imaging and Characterisation of Subsurface Solute Transport Using Electrical Resistivity Tomography (Ert) and Equivalent Transport Models. J. Hydrol. 2002, 267, 125-146.

194. Dams, J.; Dujardin, J.; Reggers, R.; Bashir, I.; Canters, F.; Batelaan, O. Mapping Impervious Surface Change from Remote Sensing for Hydrological Modeling. J. Hydrol. 2013, 485, 84-95.

195. Brunner, P.; Li, H.; Kinzelbach, W.; Li, W.; Dong, X. Extracting Phreatic Evaporation from Remotely Sensed Maps of Evapotranspiration. Water Resour. Res. 2008, 44, W08428.

196. Brunner, P.; Bauer, P.; Eugster, M.; Kinzelbach, W. Using Remote Sensing to Regionalize Local Precipitation Recharge Rates Obtained from the Chloride Method. J. Hydrol. 2004, 294, 241-250.

197. Choudhury, B.J. Synergism of Multispectral Satellite Observations for Estimating Regional Land Surface Evaporation. Remote Sens. Environ. 1994, 49, 264-274.

198. Zhou, Y.; Dong, D.; Liu, J.; Li, W. Upgrading a Regional Groundwater Level Monitoring Network for Beijing Plain, China. Geosci. Front. 2013, 4, 127-138.

199. McGuire, V.L. Water-Level and Recoverable Water in Storage Changes, High Plains Aquifer, Predevelopment To 2015 And 2013-15; 2328-0328; US Geological Survey: Reston, VA, USA, 2017.

200. Xiao, M.; Koppa, A., Mekonnen, Z., Pagán, B.R., Zhan, S., Cao, Q., Aierken, A., Lee, H. and Lettenmaier, D.P.; et al. How Much Groundwater Did California's Central Valley Lose during the 2012-2016 Drought? Geophys. Res. Lett. 2017, 44, 4872-4879.

201. Brush, C.F.; Dogrul, E.C.; Kadir, T.N. Development and Calibration of the California Central Valley Groundwater-Surface Water Simulation Model (C2vsim), Version 3.02-Cg; Bay-Delta Office, California Department of Water Resources: Sacramento, CA, USA, 2013

202. Faunt, C.C.; Belitz, K.; Hanson, R.T. Development of a Three-Dimensional Model of Sedimentary Texture in Valley-Fill Deposits of Central Valley, California, USA. Hydrogeol. J. 2010, 18, 625-649.

203. Reddy, N.S.; Saketh, M.S.; Dhar, S. Review of Sensor Technology for Mine Safety Monitoring Systems: A Holistic Approach. In Proceedings of the 2016 IEEE First International Conference on Control, Measurement and Instrumentation (CMI), Kolkata India, 8-10 January 2016; pp. 429-434.

204. Neyens, D.; Baïsset, M.; Lovighi, H. Monitoring the Groundwater Quality/Quantity from Your Desktop - Application To Salt Water Intrusion Monitoring EMI: Environmental data Management Interface. E3S Web Conf. 2018, 54, 00021.

205. Drage, J.; Kennedy, G. Building a Low-Cost, Internet-of-Things, Real-Time Groundwater Level Monitoring Network. Groundw. Monit. Remediat. 2020, 40, 67-73.

206. Alessio, B.; Walter, D.; Valerio, P.; Antonio, P. Integration of Cloud computing and Internet of Things: A survey. Future Gener. Comput. Syst. 2016, 56, 684-700, https://doi.org/10.1016/j.future.2015.09.021.

207. Fu, P.; Sun, J. Web GIS: Principles and Applications; ESRI Press: Redlands, CA, USA, 2010.

208. Li, S.; Dragicevic, S.; Veenendaal, B. Advances in Web-Based GIS, Mapping Services and Applications; CRC Press: Boca Raton, FL, USA, 2011.

209. Heywood, I.; Cornelius, S.; Carver, S. An Introduction to Geographical Information Systems; Pearson Education Limited: Harlow, UK, 2011.

210. Peng, Z.-R.; Tsou, M.-H. Internet GIS: Distributed Geographic Information Services for The Internet and Wireless Networks; John Wiley \& Sons: Hoboken, NJ, USA, 2003. 
211. Chenini, I.; Mammou, A.B. Groundwater Recharge Study in Arid Region: An Approach Using GIS Techniques and Numerical Modeling. Comput. Geosci. 2010, 36, 801-817.

212. Stefan, C.; Ansems, N. Web-Based Global Inventory of Managed Aquifer Recharge Applications. Sustain. Water Resour. Manag. 2018, 4, 153-162.

213. Maidment, D.R.; Morehouse, S. Arc Hydro: GIS For Water Resources; ESRI Inc.: Redlands, CA, USA, 2002.

214. Jones, D.; Jones, N.; Greer, J.; Nelson, J. A Cloud-Based MODFLOW Service for Aquifer Management Decision Support. Comput. Geosci. 2015, 78, 81-87.

215. Balram, S.; Dragicevic, S. Collaborative Geographic Information Systems: Origins, Boundaries, And Structures. In Collaborative Geographic Information Systems; IGI Global: Hershey, PA, USA, 2006; pp. 1-23.

216. Werner, M.; Schellekens, J.; Gijsbers, P.; van Dijk, M.; van den Akker, O.; Heynert, K. The Delft-FEWS Flow Forecasting System. Environ. Model. Softw. 2013, 40, 65-77.

217. Hsu, Y.-C.; Chang, Y.-L.; Chang, C.-H.; Yang, J.-C.; Tung, Y.-K. Physical-Based Rainfall-Triggered Shallow Landslide Forecasting. Smart Water 2018, 3, 3.

218. Foglia, L.; Borsi, I.; Mehl, S.; De Filippis, G.; Cannata, M.; Vasquez-Suñe, E.; Criollo, R.; Rossetto, R. FREEWAT, A Free And Open Source, GIS-Integrated, Hydrological Modeling Platform. Groundwater 2018, 56, 521-523.

219. Rossetto, R.; De Filippis, G.; Borsi, I.; Foglia, L.; Cannata, M.; Criollo, R.; Vázquez-Suñé, E. Integrating Free and Open Source Tools and Distributed Modelling Codes in GIS Environment for Data-Based Groundwater Management. Environ. Model. Softw. 2018, 107, 210-230.

220. De Filippis, G.; Pouliaris, C.; Kahuda, D.; Vasile, T.A.; Manea, V.A.; Zaun, F.; Panteleit, B.; Dadaser-Celik, F.; Positano, P.; Nannucci, M.S.; et al. Spatial Data Management and Numerical Modelling: Demonstrating the Application of the QGIS-Integrated FREEWAT Platform at 13 Case Studies for Tackling Groundwater Resource Management. Water 2020, 12, 41.

221. Snow, A.D.; Christensen, S.D.; Swain, N.R.; Nelson, E.J.; Ames, D.P.; Jones, N.L.; Ding, D.; Noman, N.S.; David, C.H.; Pappenberger, F.; et al. A High-Resolution National-Scale Hydrologic Forecast System from a Global Ensemble Land Surface Model. J. Am. Water Resour. Assoc. 2016, 52, 950-964.

222. Morsy, M.M.; Goodall, J.L.; Castronova, A.; Dash, P.; Merwade, V.; Sadler, J.M.; Rajib, M.A.; Horsburgh, J.S.; Tarboton, D. Design of a Metadata Framework for Environmental Models with an Example Hydrologic Application in HydroShare. Environ. Model. Softw. 2017, 93, 13-28.

223. Swain, N.R.; Christensen, S.D.; Snow, A.; Dolder, H.; Espinoza-Dávalos, G.; Goharian, E.; Jones, N.L.; Nelson, E.J.; Ames, D.P.; Burian, S. A New Open Source Platform for Lowering the Barrier for Environmental Web App Development. Environ. Model. Softw. 2016, 85, 11-26.

224. MAGNET. MAGNET4water. Available online: https://www.magnet4water.net/ (accessed on 31 July 2021).

225. Malche, T.; Maheshwary, P. Internet of Things (IoT) Based Water Level Monitoring System for Smart Village. In Proceedings of the International Conference on Communication and Networks, Vancouver, BC, Canada, 31 July-3 August 2017; Springer: Berlin/Heidelberg, Germany, 2017; pp. 305-312.

226. Horsburgh, J.S.; Morsy, M.M.; Castronova, A.; Goodall, J.; Gan, T.; Yi, H.; Stealey, M.J.; Tarboton, D.G. Hydroshare: Sharing Diverse Environmental Data Types and Models as Social Objects with Application to the Hydrology Domain. J. Am. Water Resour. Assoc. 2016, 52, 873-889.

227. Brewer, E.A. Towards Robust Distributed Systems. In Proceedings of the Nineteenth Annual ACM Symposium on Principles of Distributed Computing, Portland, OR, USA, 16-19 July 2000; Volume 7, pp. 343477-343502.

228. Hung, H.-C.; Liu, I.-F.; Liang, C.-T.; Su, Y.-S. Applying Educational Data Mining to Explore Students' Learning Patterns in the Flipped Learning Approach for Coding Education. Symmetry 2020, 12, 213.

229. Lai, Y.-H.; Chen, S.-Y.; Lai, C.-F.; Chang, Y.-C.; Su, Y.-S. Study on Enhancing AIoT Computational Thinking Skills by Plot ImageBased VR. Interact. Learn. Environ. 2019, 29, 482-495.

230. Anumalla, S.; Ramamurthy, B.; Gosselin, D.C.; Burbach, M. Groundwater Monitoring Using Smart Sensors. In Proceedings of the 2005 IEEE International Conference on Electro Information Technology, Lincoln, NE, USA, 22-25 May 2005; p. 6.

231. Afifi, M.; Abdelkader, M.F.; Ghoneim, A. An IoT System for Continuous Monitoring and Burst Detection in Intermittent Water Distribution Networks. In Proceedings of the 2018 International Conference on Innovative Trends in Computer Engineering (ITCE), Aswan, Egypt, 19-21 February 2018; pp. 240-247.

232. Kamaruidzaman, N.; Rahmat, S.N. Water Monitoring System Embedded with the Internet of Things (IoT) Device: A Review. IOP Conf. Ser. Earth Environ. Sci. 2020, 498, 012068.

233. Tauro, F.; Selker, J.; van de Giesen, N.; Abrate, T.; Uijlenhoet, R.; Porfiri, M.; Manfreda, S.; Caylor, K.; Moramarco, T.; Benveniste, J.; et al. Measurements and Observations in the XXI century (MOXXI): Innovation and Multi-disciplinarity to Sense the Hydrological Cycle. Hydrol. Sci. J. 2018, 63, 169-196.

234. Mesquita, E.; Paixão, T.; Antunes, P.; Coelho, F.; Ferreira, P.; Andre, P.; Varum, H. Groundwater Level Monitoring Using a Plastic Optical Fiber. Sens. Actuators A Phys. 2016, 240, 138-144.

235. Verma, P.; Kumar, A.; Rathod, N.; Jain, P.; Mallikarjun, S.; Subramanian, R.; Amrutur, B.; Kumar, M.M.; Sundaresan, R. Towards an IoT Based Water Management System for a Campus. In Proceedings of the 2015 IEEE First International Smart Cities Conference (ISC2), Guadalajara, Mexico, 25-28 October 2015; pp. 1-6.

236. Odli, Z.S.M.; Izhar, T.N.T.; Razak, A.R.A.; Yusuf, S.Y.; Zakarya, I.A.; Saad, F.N.M.; Nor, M.Z.M. Development of Portable Water Level Sensor for Flood Management System. ARPN J. Eng. Appl. Sci. 2016, 11, 5352-5357. 